\title{
Melatonin for the prevention and treatment of cancer
}

Review

\author{
Ya Li ${ }^{1}$, Sha $\mathrm{Li}^{2, *}$, Yue Zhou ${ }^{1}$, Xiao Meng ${ }^{1}$, Jiao-Jiao Zhang ${ }^{1}$, Dong-Ping Xu ${ }^{1}$ and Hua- \\ Bin Li ${ }^{1,3}$,* \\ ${ }^{1}$ Guangdong Provincial Key Laboratory of Food, Nutrition and Health, Department of Nutrition, School of Public Health, Sun \\ Yat-Sen University, Guangzhou, China \\ ${ }^{2}$ School of Chinese Medicine, Li Ka Shing Faculty of Medicine, The University of Hong Kong, Hong Kong, China \\ 3 South China Sea Bioresource Exploitation and Utilization Collaborative Innovation Center, Sun Yat-Sen University, \\ Guangzhou, China \\ Correspondence to: Hua-Bin Li, email: lihuabin@mail.sysu.edu.cn \\ Sha Li, email: u3003781@connect.hku.hk \\ Keywords: melatonin; anticancer; mechanisms of action; receptor; apoptosis \\ Received: January 20, $2017 \quad$ Accepted: March 09, $2017 \quad$ Published: March 18, 2017
}

Copyright: Li et al. This is an open-access article distributed under the terms of the Creative Commons Attribution License (CC-BY), which permits unrestricted use, distribution, and reproduction in any medium, provided the original author and source are credited.

\section{ABSTRACT}

The epidemiological studies have indicated a possible oncostatic property of melatonin on different types of tumors. Besides, experimental studies have documented that melatonin could exert growth inhibition on some human tumor cells in vitro and in animal models. The underlying mechanisms include antioxidant activity, modulation of melatonin receptors MT1 and MT2, stimulation of apoptosis, regulation of pro-survival signaling and tumor metabolism, inhibition on angiogenesis, metastasis, and induction of epigenetic alteration. Melatonin could also be utilized as adjuvant of cancer therapies, through reinforcing the therapeutic effects and reducing the side effects of chemotherapies or radiation. Melatonin could be an excellent candidate for the prevention and treatment of several cancers, such as breast cancer, prostate cancer, gastric cancer and colorectal cancer. This review summarized the anticancer efficacy of melatonin, based on the results of epidemiological, experimental and clinical studies, and special attention was paid to the mechanisms of action.

\section{INTRODUCTION}

Melatonin (N-acetyl-5-methoxytryptamine, Figure 1) is an indolic compound secreted primarily by the pineal gland of human and mammals in response to darkness [1]. Except for the pineal, melatonin synthesis is also found in several other organs, including the retina, gastrointestinal tract, skin, bone marrow, and lymphocytes [2]. The process of melatonin biosynthesis and metabolism is shown in Figure 2, and only the primary metabolite 6-sulphatoxymelatonin (aMT6s) is included, because it is commonly used as the maker of circadian melatonin level [3-5]. The synthesis and secretion of melatonin are regulated by the 'master biological clock' located in the suprachiasmatic nucleus (SCN) of the hypothalamus [6]. Although melatonin is regulated by central circadian clock, it could also modulate central circadian clock and peripheral oscillators in tissues and organs, which makes melatonin a marker of circadian rhythms [7].
The melatonin level elevates at night and decreases throughout the day. Studies have shown that increased nighttime melatonin levels in the blood could send signals to the body's cells and organs that it is nighttime and help organize target organs and organ systems into appropriate homeostatic metabolic rhythms [8]. Therefore, light at night (LAN) could disrupt the circadian rhythm and the melatonin production [9], which could contribute to the development, promotion, and progression of cancers.

According to the data reported by WHO, cancer is the leading cause of worldwide morbidity and mortality, with approximately 14 million new cases and 8.2 million cancer associated deaths in 2012 [10]. In the USA alone, it's estimated that in 2016, 1,685,210 new cancer cases and 595,690 cancer deaths could occur [11]. Nowadays, patients with cancer mainly count on clinical treatment, e.g. surgery, radiotherapy and chemotherapy. In addition, some natural products showed the potential for prevention and treatment of cancers [12-21]. Studies on cancer and anticancer therapies have attracted great attention. 
In the last decades, accumulating evidence has outlined the relevance of melatonin to human physiology and pathology. Now it is well accepted that melatonin is not only a hormone, but also a cell protector [22], involved in immunomodulation, antioxidative processes, and hematopoiesis [23, 24]. Moreover, a bunch of studies have shown that melatonin has important oncostatic properties, through receptor-dependent and receptor-independent mechanisms [25]. The melatonin receptors MT1 (encoded by MTNR1A) and MT2 (encoded by MTNR1B) belong to the G-protein-coupled receptor (GPCR) group [26], and are mainly responsible for mediating the downstream effects of melatonin [27]. For incidence, they are involved in inhibition of adenyl cyclase and cyclic AMP (cAMP), leading to a reduction in uptake of linoleic acid. Melatonin-induced inhibition on linoleic acid uptake is considered as a mechanism of its antiproliferative effects [28]. The receptor-independent mechanisms are associated with antioxidant activity, regulation of apoptosis, tumor metabolism and cancer immunity, inhibition on angiogenesis and migration, and prevention of circadian disruption [25, 29, 30]. Melatonin also showed the potential to be utilized as adjuvant of cancer therapies, through reinforcing the therapeutic effects and reducing the side effects of chemotherapies or radiation [31].

The objective of the present review is to summarize recent discoveries on the oncostatic property of melatonin, classified by hormone-dependent cancers and hormoneindependent cancers, and to discuss the mechanisms of action, based on the results of epidemiological research, experimental studies and clinical trials.

\section{EPIDEMIOLOGICAL STUDIES}

Several epidemiological studies support a protective role of melatonin in cancer, yet not all the epidemiological studies are consistent (Table 1). Some studies suggested an inverse association between circadian melatonin level and breast cancer incidence. According to a doseresponse analysis of observational studies, high artificial LAN exposure was related with an increased risk of breast cancer $(\mathrm{RR}=1.17,95 \% \mathrm{CI}: 1.11-1.23)$, and risk of breast cancer was reduced by $14 \%$ with an increase of $15 \mathrm{ng} / \mathrm{mg}$ creatinine in urinary aMT6s $(\mathrm{RR}=0.86,95 \% \mathrm{CI}: 0.78$ $0.95)$, with a linear dose-response trend $(\mathrm{P}$-trend $=0.003$ ) [32]. In addition, a case-control study found that female subjects with serum melatonin levels $\leq 39.5 \mathrm{pg} / \mathrm{mL}$ had a significantly higher risk of breast cancer incidence (about 15 folds) compared with subjects with levels $>39.5 \mathrm{pg} / \mathrm{mL}$ $(\mathrm{OR}=14.24 ; 95 \% \mathrm{CI}=4.32-46.90)$. Meanwhile, the GG genotype of the MTNR1b (encoding melatonin receptor MT2) gene rs\#10830963 polymorphism significantly elevated the risk of breast cancer by about 21 times more than the $\mathrm{CC}$ genotype $(\mathrm{OR}=20.67 ; 95 \% \mathrm{CI}=4.77-99.33)$ [33]. Besides, a meta-analysis including 5 prospective case-control studies reported an inverse relationship between breast cancer risk and the highest levels of urinary aMT6s [34]. Another study evaluated the association between breast cancer risk and common single nucleotide polymorphismsin the MTNR1a, MTNR1b, and AANAT (encoding arylalkylamine $\mathrm{N}$-acetyltransferase) genes among 2,073 cases and 2,083 controls, and reported that common genetic variation in the MTNR $1 a$ and MTNR $1 b$ genes might contribute to breast cancer susceptibility, and the associations might vary with menopausal status [27]. A nested case-control study reported that a higher urinary aMT6s level was significantly associated with a lower risk of breast cancer $(\mathrm{OR}=0.62 ; 95 \% \mathrm{CI}, 0.41-0.95$; $\mathrm{P}($ trend $)=0.004)$ [35]. However, 4 case-control studies suggested there was no evidence that melatonin level was associated with breast cancer risk. A prospective nested case-control study among British women pointed out that no statistically significant differences in urinary aMT6s level between women with breast cancer and healthy women were observed, regardless of menopausal status [36]. Besides, a case-control study nested in the Women's Health Initiative Observational Cohort reported there was no evidence that higher urinary levels of melatonin were inversely related with breast cancer risk in postmenopausal women [37]. Results from another case-control study nested within the Nurses' Health Study II cohort also did not support an overall association between urinary melatonin levels and breast cancer risk [38]. Likewise, no significant association was found between aMT6s level and breast cancer risk (either overall or by menopausal status) in a case-control study nested in the Guernsey III Study [39].

As for cancers other than breast cancer, a casecohort study reported that men with first morning urinary aMT6s levels below the median possessed a fourfold higher risk of prostate cancer compared with men with levels above the median (HR: 4.04; 95\% CI: 1.26-12.98) [40]. In addition, a case-control study pointed out that patients with high melatonin-sulfate levels or a high melatonin-sulfate/cortisol ratio were less likely to have prostate cancer (adjusted OR $(\mathrm{aOR})=0.59,95 \% \mathrm{CI}: 0.35$ $0.99 ; \mathrm{aOR}=0.46,95 \% \mathrm{CI}: 0.27-0.77)$ or advanced stage prostate $(\mathrm{aOR}=0.49,95 \% \mathrm{CI}=0.26-0.89 ; \mathrm{aOR}=0.33$, $95 \% \mathrm{CI}=0.17-0.62$ ) [41]. A retrospective study found that the serum melatonin levels in women with ovarian

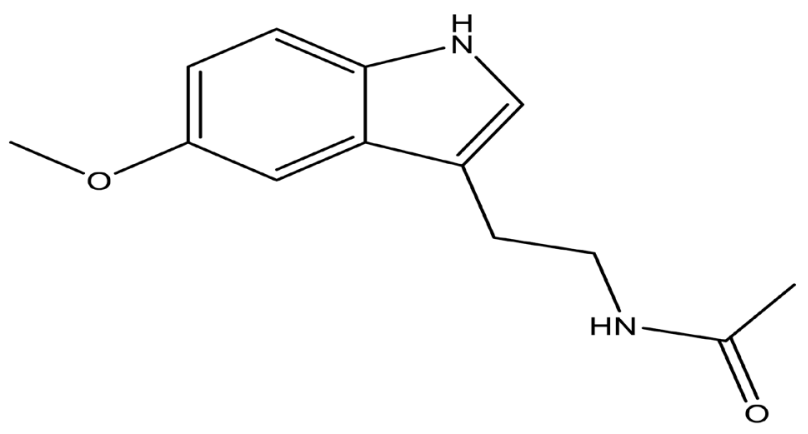

Figure 1: Structure of melatonin. 
cancer were significantly lower compared with control subjects $(p<0.05)$, indicating that reduction in circulating melatonin level might contribute to the pathogenesis of ovarian cancer [42]. Besides, according to a meta-analysis of RCTs, melatonin significantly improved the complete and partial remission ( 16.5 vs. $32.6 \%$; RR $=1.95,95 \%$ CI: $1.49-2.54 ; p<0.00001), 1$-year survival rate $(28.4$ vs. $52.2 \%$; RR $=1.90 ; 95 \%$ CI: $1.28-2.83 ; p=0.001$ ) for solid tumors, and markedly decreased side effects induced by radiochemotherapy, including neurotoxicity, thrombocytopenia, and fatigue. Meanwhile, effects were accordant across different types of cancers [43]. Similarly, another meta-analysis summarizing 21 clinical trials, which all dealt with solid tumors, revealed that melatonin as an adjuvant cancer care with chemotherapy decreased 1-year mortality $(\mathrm{RR}=0.60 ; 95 \% \mathrm{CI}: 0.54-0.67)$, and reduced chemotherapy-induced symptoms such as asthenia, leucopenia, nausea, vomiting, and hypotension [44]. However, a nested case-control study showed that no obvious association between urinary melatonin level and ovarian cancer risk was observed [45].

It should be noted that in the existing epidemiological studies, the methods of melatonin assessment are not uniformed, since melatonin concentrations were measured in different samples, such as urine, plasma or serum. Moreover, the melatonin concentration in human body changes with circadian rhythm, however, it has not been determined which sample collection time could best reflect the biological effects of melatonin. These differences might partially result in the inconsistence of epidemiological studies. In this case, the laboratory study in cell culture or on animal models might be more clear and direct to assess the anticancer effect

\section{Tryptophan Hydroxylase}

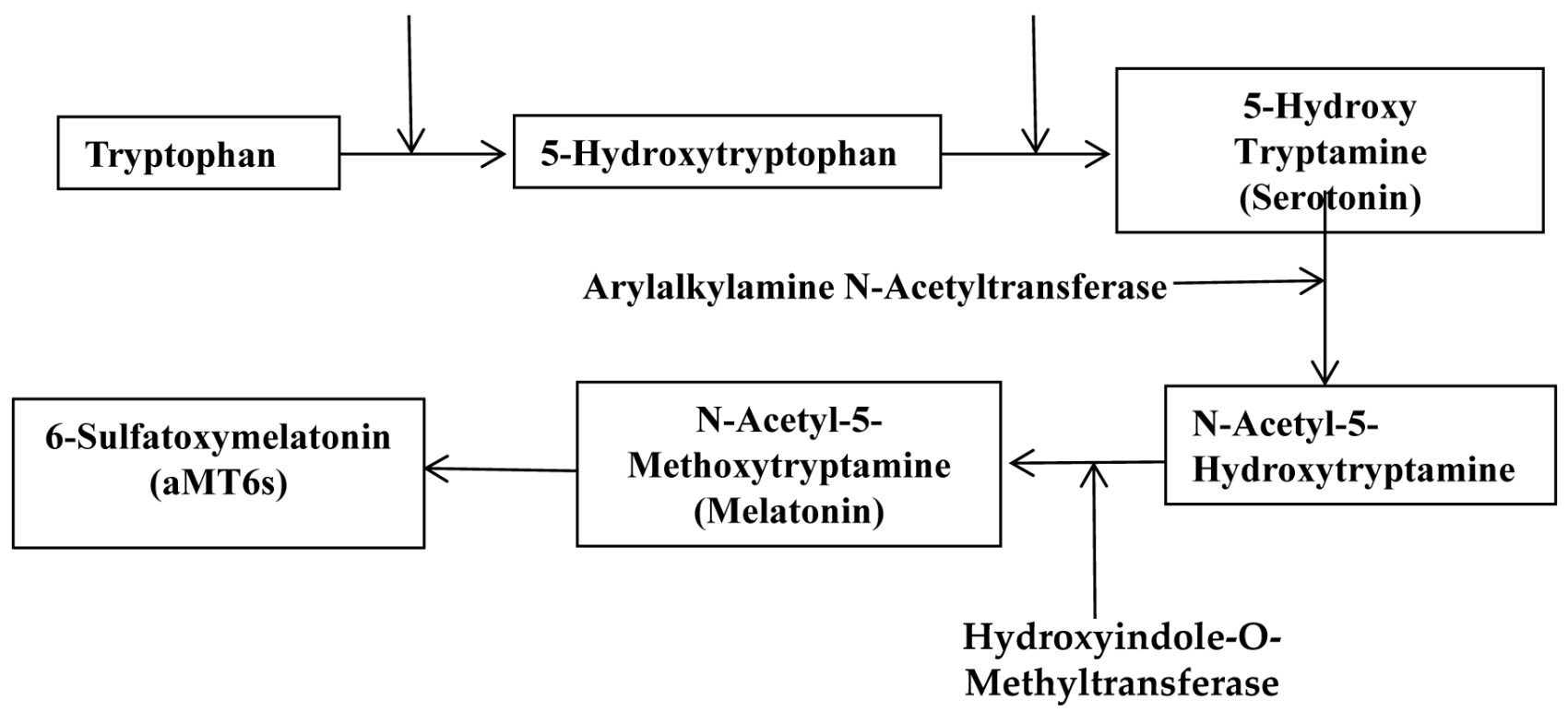

of melatonin and investigate the possible mechanisms involved in this process.

\section{EXPERIMENTAL STUDIES}

Accumulating evidence from experimental studies has supported the anticancer properties of melatonin. Given the vast number of studies, publications in the PubMed and Web of Science databases were searched and relevant peer-reviewed articles published in English within 5 years were identified.

\section{Hormone-dependent cancer}

\section{Breast cancer}

Breast cancer is one of the most common cancers in women, and one of the leading causes of death for women aged 40 to 55 years [46] . Research concerning the melatonin's effects on breast cancer is the largest, possibly due to that melatonin has shown to modulate several aspects of endocrine physiology. Early studies reported that melatonin produced antiproliferative effect in breast cancer cells in vitro [47], and inhibited the growth of mammary tumors in rats [48, 49]. Afterwards, different mechanisms of melatonin's anticancer effects were identified successively, such as inducing apoptosis [50], antiestrogenic effect through ER $\alpha$-signaling pathway and inhibiting aromatase activity [51-53], modulation of melatonin receptors [54], and inhibition on invasion [55] and angiogenesis [56].

\section{5-Hydrotryptophen Decarboxylase}

\section{Methyltransferase}

Figure 2: The biosynthesis and metabolism process of melatonin. 


\section{In vitro studies}

Melatonin presented an anti-metastatic effect on CMT-U229 and MCF-7 breast cancer cell lines, through inhibiting the viability and invasiveness of breast cancer mammospheres and also mediating expression of epithelial mesenchymal transition (EMT) related proteins [57]. The anti-invasive effect of melatonin on breast cancer was also through down-regulation of the p38 pathway and suppression of MMP-2 and -9 expression and activity [58]. Melatonin also decreased proliferation and viability and induced apoptosis in neoplastic mammary cells, with better efficacy in ER-positive tumors which presented a high expression of melatonin receptor MT1 [59]. In addition, melatonin exhibited an antiproliferative activity and stimulated apoptosis in breast cancer cell MDA-MB-361, through a simultaneous modulation of the COX-2/PGE2, p300/NF- $\mathrm{kB}$, and PI3K/Akt/signaling and activation of the Apaf-1/caspase-dependent apoptotic pathway [60].

It has been demonstrated that melatonin might control tumor growth in advanced cancer patients, which was at least in part through functioning as a natural antiangiogenic molecule as evidenced by decreased blood VEGF levels [61]. For breast cancer, $1 \mathrm{nM}$ melatonin reduced the viability of hypoxic MCF-7 and MDAMB-231 human breast cancer cells and decreased both gene and protein expression of HIF- $1 \alpha$ and VEGF-A $(p<0.05)$, indicating an anti-angiogenesis effect [56]. Additionally, Alvarez-Garcia et al. reported the anti- angiogenesis effect of melatonin by downregulation of VEGF expression in human breast cancer cells, which decreased the levels of VEGF around endothelial cell [62]. Another study also observed that melatonin was effective in controlling tumor angiogenesis [63].

Melatonin could inhibit aromatase activity in breast cancer cells. Melatonin of $20 \mathrm{nM}$ generated an antiaromatase effect as potent as $20 \mathrm{nM}$ letrozole, which is a selective estrogen enzyme modulator and clinically used anti-aromatase drug in breast cancer treatment [64]. A possible mechanism of melatonin's anti-aromatase effect was through inhibition on COX activity and expression [65]. Likewise, melatonin treatment exerted significant inhibition on CYP19A1 gene transcription and aromatase activity on breast adipose fibroblasts and breast cancerassociated fibroblasts [66]. Besides, melatonin could interfere with the desmoplastic reaction in breast cancer, via down-regulating the expression of anti-adipogenic cytokines, which could promote the differentiation of fibroblasts and produce an anti-aromatase action, thereby decreasing the number of estrogen-producing cells proximal to malignant cells [67].

A group reported that melatonin could induce differential expression of miRNA and miRNA-related genes in human breast cancer cells, indicating an oncostatic effect [68, 69]. Furthermore, they reported that melatonin treatment expressed an anticancer effect through influencing DNA methylation patterns, by downregulating oncogenic genes (EGR3 and POU4F2/Brn-3b) and up-regulating the tumor suppressor gene (GPC3) [70].

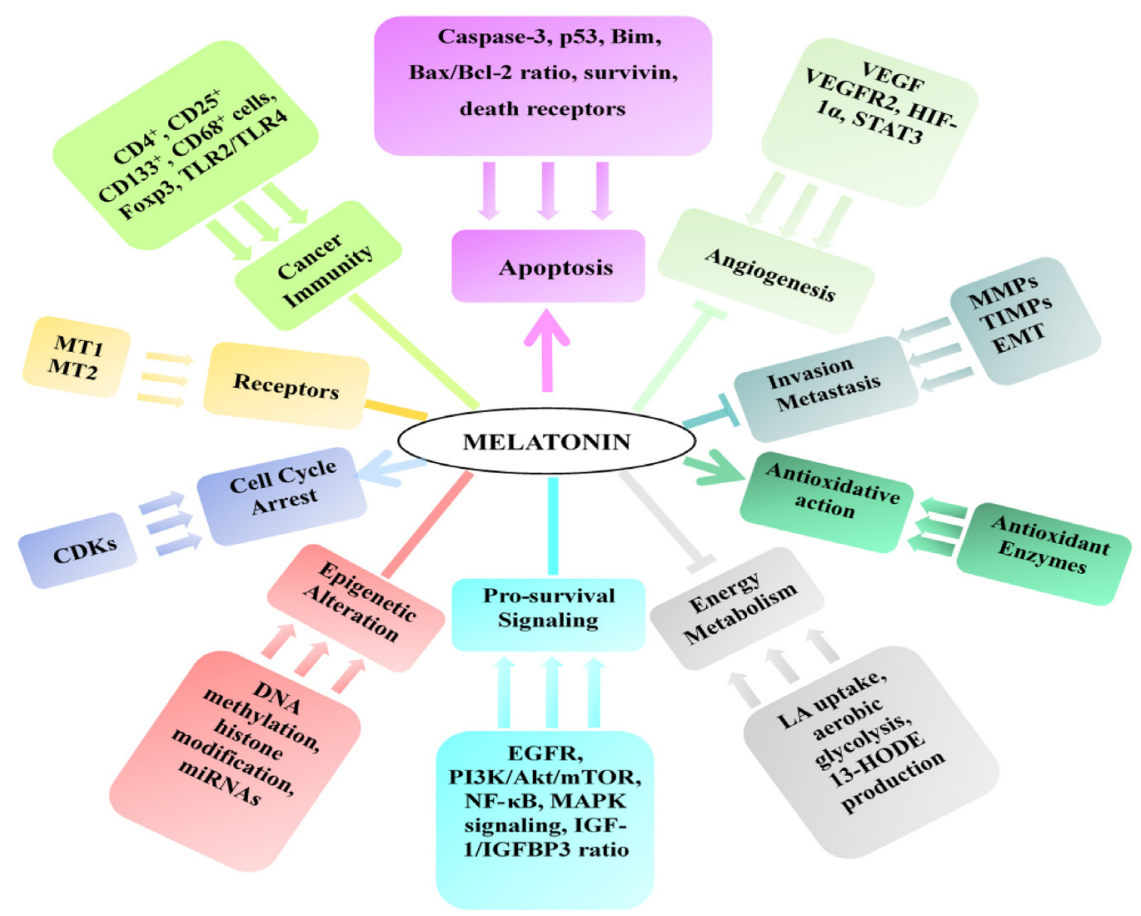

Figure 3: Mechanisms of the anticancer effect of melatonin. $\rightarrow$ stands for promotion, - stands for regulation, and - stands for inhibition. 
Table 1: Epidemiological studies on melatonin level and cancer risks

\begin{tabular}{|c|c|c|c|}
\hline Cancer & Study Type & Association & Ref. \\
\hline breast cancer & dose-response analysis of observational studies & $\begin{array}{l}\mathrm{RR}=0.86 \\
95 \% \mathrm{CI}=0.78-0.95\end{array}$ & {$[32]$} \\
\hline breast cancer & case-control study & $\begin{array}{l}\mathrm{OR}=14.24 \\
95 \% \mathrm{CI}=4.32-46.90\end{array}$ & [33] \\
\hline breast cancer & meta-analysis & $\begin{array}{l}\text { fixed effects model: } 95 \% \mathrm{CI}= \\
0.71-0.95, p=0.01 ; \\
\text { random effects model: } 95 \% \mathrm{CI}= \\
0.68-0.99, \mathrm{p}=0.04\end{array}$ & {$[34]$} \\
\hline breast cancer & case-control study & $\begin{array}{l}\text { premenopausal women: } \mathrm{OR}= \\
1.57,95 \% \mathrm{CI}=1.07-2.31, p= \\
0.020 ; \\
\text { postmenopausal women: } \mathrm{OR}= \\
0.58,95 \% \mathrm{CI}=0.36-0.95, p= \\
0.030\end{array}$ & {$[27]$} \\
\hline breast cancer & nested case-control study & $\begin{array}{l}\mathrm{OR}=0.62 ; 95 \% \text { CI, 0.41-0.95; } \\
p=0.004\end{array}$ & {$[35]$} \\
\hline breast cancer & nested case-control study & no significant association & {$[36]$} \\
\hline breast cancer & case-control study & no significant association & [37] \\
\hline breast cancer & case-control study & no significant association & [38] \\
\hline breast cancer & case-control study & no significant association & [39] \\
\hline prostate cancer & case-cohort study & $\begin{array}{l}\mathrm{HR}=4.04 \\
95 \% \text { CI: } 1.26-12.98\end{array}$ & [40] \\
\hline prostate cancer & case-control study & $\begin{array}{l}\text { prostate cancer: } \mathrm{aOR}=0.59,95 \% \\
\text { CI: } 0.35-0.99 \\
\text { advanced stage prostate: } \mathrm{aOR}= \\
0.49, \\
95 \% \mathrm{CI}=0.26-0.89\end{array}$ & [41] \\
\hline ovarian cancer & retrospective study & $p<0.05$ & [42] \\
\hline solid tumors & meta-analysis & $\begin{array}{l}\text { 1-year survival rate: } \mathrm{RR}=1.90 \text {; } \\
95 \% \mathrm{CI}=1.28-2.83\end{array}$ & [43] \\
\hline solid tumors & meta-analysis & $\begin{array}{l}\mathrm{RR}=0.60 \\
95 \% \mathrm{CI}=0.54-0.67\end{array}$ & [44] \\
\hline ovarian cancer & case-control study & no significant association & {$[45]$} \\
\hline
\end{tabular}

Besides, long-term treatment of melatonin could suppress proliferation and migration of breast cancer cells partially through downregulation of miR-24, which was regarded as a potential diagnostic tumor marker [71]. Treating MT1-transfected MCF-7 cells with melatonin could lead to a significant amplified growth-inhibition, while MT1transfected MDA-MB-231 cells showed no response to melatonin, indicating the mediation role of MT1 receptor in melatonin's oncostatic activity [72]. Additionally, among 3 ER-negative breast cancer cell lines, only the proliferation of SK-BR-3 cells was inhibited by melatonin, despite that MT1 receptor was expressed in all three cell lines [73].

The synergetic effect of melatonin with other anticancer drugs or radiotherapy is also noteworthy. Melatonin enhanced the effects of doxorubicin by activating transient receptor potential vanilloid 1 (TRPV1) and apoptosis as well as inducing MCF-7 cell death [74]. In addition, melatonin enhanced the apoptotic cell death induced by arsenic trioxide via ROS generation, upregulation of Redd1 expression, and activation of the p38/JNK pathways in human breast cancer cells [75].
Besides, melatonin ( $3 \mathrm{mM})$ combined with puromycin (1 $\mu \mathrm{M})$ exerted synergistically inhibitory effect on MDA-MB 231 cells, through attenuating the expression of $45 \mathrm{~S}$ prerRNA and upstream binding factor, and downregulating upstream binding factor, XPO1 and IPO7, procaspase 3, and Bcl-xL [76]. Furthermore, combined treatment of melatonin with all-trans retinoic acid and somatostatin enhanced the inhibitory effect on viability and growth of MCF-7 cells [77]. In addition, melatonin combined with vitamin $\mathrm{D}_{3}$ synergistically inhibited proliferation with an almost complete cell growth arrest in MCF-7 cells [78]. Melatonin could also enhance the radiosensitivity of cancer cells. Pretreatment with melatonin on MCF-7 breast cancer cells 1 week before radiation could sensitize cancer cells to the ionizing effects of radiation, through inhibiting proliferation, promoting cell cycle arrest and inhibiting proteins involved in double-strand DNA break repair [79]. Another study suggested the enhancing effect of melatonin on the radiosensitivity of human breast cancer cells might be associated with the increase of p53 expression [80]. 
Table 2: The in vitro and in vivo effects of melatonin on hormone-dependent cancers

\begin{tabular}{|c|c|c|c|c|c|}
\hline Study Type & Subject & Dose & Main Effect & Possible Mechanisms & Ref. \\
\hline \multicolumn{6}{|c|}{ Breast Cancer } \\
\hline in vitro & CMT-U229 and MCF-7 cells & $1 \mathrm{mM}$ & inhibiting cancer cell metastasis & NA & {$[57]$} \\
\hline in vitro & $\begin{array}{l}\text { MCF-7/6, MCF-7/Her2.1, and } \\
\text { MCF-7/CXCR } 4 \text { cells }\end{array}$ & $10^{-9} \mathrm{M}$ & inhibiting cancer cell invasion & $\begin{array}{l}\text { down-regulation of the p38 pathway } \\
\text { and suppression of MMP-2 and }-9 \\
\text { expression and activity }\end{array}$ & {$[58]$} \\
\hline in vitro & $\begin{array}{l}10 \text { canine mammary tumor } \\
\text { fragments }\end{array}$ & $\begin{array}{l}0.5,1,2,5,10 \\
\mathrm{mM}\end{array}$ & $\begin{array}{l}\text { decreasing proliferation and } \\
\text { viability and inducing apoptosis }\end{array}$ & NA & [59] \\
\hline in vitro & MDA-MB-361 cells & $1 \mathrm{mM}$ & $\begin{array}{l}\text { inhibiting cell proliferation and } \\
\text { inducing apoptosis }\end{array}$ & $\begin{array}{l}\text { COX-2/PGE2, p300/NF-kB, and } \\
\text { PI3K/Akt/signaling; activation of } \\
\text { Apaf-1/caspase-dependent apoptotic } \\
\text { pathway }\end{array}$ & {$[60]$} \\
\hline in vitro & MCF-7 and MDA-MB-231 cells & $1 \mathrm{nM}$ & anti-angiogenesis effect & NA & {$[56]$} \\
\hline in vitro & MCF-7 cells & $1 \mathrm{mM}$ & anti-angiogenesis effect & NA & [62] \\
\hline in vitro & MDA-MB-231 cells & $1 \mathrm{mM}$ & anti-angiogenesis effect & NA & [63] \\
\hline in vitro & T47D cell & $20 \mathrm{nM}$ & anti-aromatase effect & $\begin{array}{l}\text { acting as a selective estrogen enzyme } \\
\text { modulators }\end{array}$ & {$[64]$} \\
\hline in vitro & in vitro & $1 \mathrm{nM}$ & anti-aromatase effect & $\begin{array}{llll}\begin{array}{l}\text { inhibiting } \\
\text { activity }\end{array} & & \\
\end{array}$ & {$[65]$} \\
\hline in vitro & $\begin{array}{ll}\text { breast } & \text { cancer-associated } \\
\text { fibroblasts } & \end{array}$ & $\begin{array}{l}10 \mathrm{pM}, 1 \mathrm{nM}, \\
10 \mu \mathrm{M}\end{array}$ & $\begin{array}{l}\text { inhibiting aromatase expression } \\
\text { and activity }\end{array}$ & inhibiting $C Y P 19 A 1$ gene transcription & {$[66]$} \\
\hline in vitro & MCF-7 cells & $1 \mathrm{mM}$ & $\begin{array}{l}\text { decreasing aromatase activity and } \\
\text { expression }\end{array}$ & $\begin{array}{l}\text { interfering with the desmoplastic } \\
\text { reaction via downregulating the anti- } \\
\text { adipogenic cytokines }\end{array}$ & {$[67]$} \\
\hline in vitro & MCF-7 cells & $1 \mathrm{nM}, 100 \mathrm{nM}$ & inhibiting growth of cancer cells & $\begin{array}{l}\text { inducing differential expression of } \\
\text { miRNA and miRNA-related genes }\end{array}$ & {$[68,69]$} \\
\hline in vitro & MCF-7 cells & $1 \mathrm{nM}$ & $\begin{array}{l}\text { growth inhibition effect on cancer } \\
\text { cells }\end{array}$ & influencing DNA methylation patterns & {$[70]$} \\
\hline in vitro & MCF-7 cells & $1 \mu \mathrm{M}$ & $\begin{array}{l}\text { inhibiting cell proliferation and } \\
\text { migration }\end{array}$ & downregulation of miR-24 & [71] \\
\hline in vitro & MCF-7 cells & $\begin{array}{l}1 \mathrm{nM}, 100 \mathrm{nM} \\
\text { and } 10 \mathrm{mM}\end{array}$ & inhibiting cell proliferation & overexpressing of MT1 receptors & {$[72]$} \\
\hline in vitro & $\begin{array}{l}\text { MDA-MB-231, BT-20, SK-BR-3 } \\
\text { cells }\end{array}$ & $10^{-9} \mathrm{M}$ & $\begin{array}{l}\text { inhibiting proliferation of cancer } \\
\text { cell }\end{array}$ & NA & [73] \\
\hline in vitro & MCF-7 and MDA-MB-231 cells & $0.0001-1 \mathrm{~mm}$ & \multirow{2}{*}{ controlling metastasis } & \multirow{2}{*}{ modulation of ROCK-1 expression } & \multirow{2}{*}[81]{} \\
\hline in vivo & athymic nude mice & $100 \mathrm{mg} / \mathrm{kg}$ bw & & & \\
\hline in vitro & MDA-MB-231 cells & $0.0001-1 \mathrm{~mm}$ & decreasing cell viability & \multirow[b]{2}{*}{ anti-angiogenesis effect } & \multirow[b]{2}{*}{ [82] } \\
\hline in vivo & athymic nude mice & $40 \mathrm{mg} / \mathrm{kg}$ bw & $\begin{array}{l}\text { reducing tumor size and cell } \\
\text { proliferation }\end{array}$ & & \\
\hline in vivo & $\mathrm{BALB} / \mathrm{c}$ mice & $\begin{array}{l}33 \mathrm{mg} / \mathrm{L} \text { in } \\
\text { drinking water }\end{array}$ & $\begin{array}{l}\text { decreasing tumor growth rate } \\
\text { induced by LAN }\end{array}$ & global DNA methylation & [83] \\
\hline in vivo & rats & $\begin{array}{l}\text { human } \\
\text { melatonin-rich } \\
\text { blood }\end{array}$ & affecting cancer cell invasion & activating GSK3 $\beta$ & {$[84]$} \\
\hline \multicolumn{6}{|c|}{ Prostate Cancer } \\
\hline in vitro & PC-3 cells & $1 \mathrm{mM}$ & anti-angiogenesis effect & $\begin{array}{l}\text { upregulation of miRNA3195 and } \\
\text { miRNA374b }\end{array}$ & [93] \\
\hline in vitro & LNCaP, 22Rv1 cells & $10^{-8} \mathrm{M}$ & inhibiting proliferation & $\begin{array}{l}\text { MT1 receptor-mediated inactivation } \\
\text { of NF- } \mathrm{B} \text {. }\end{array}$ & {$[94,95]$} \\
\hline in vitro & PC-3 cells & $1 \mathrm{nM}$ or $1 \mathrm{mM}$ & suppressing HIF-1 $\alpha$ accumulation & $\begin{array}{|ll|}\begin{array}{l}\text { inactivating } \\
\text { pathway and scavenging }\end{array} \text { sing free radicals } & 1 \\
\end{array}$ & {$[96]$} \\
\hline in vitro & multiple cancer cell lines & $10 \mathrm{nM}-2 \mathrm{mM}$ & reducing proliferative potential & suppressing Sirt1 activity & [98] \\
\hline in vitro & LNCaP cells & $1 \mathrm{mM}$ & $\begin{array}{l}\text { sensitizing cancer cells to } \\
\text { cytokines-induced apoptosis }\end{array}$ & $\begin{array}{l}\text { causing phenotypic changes, mainly } \\
\text { neuroendocrine differentiation }\end{array}$ & [99] \\
\hline in vitro & $\begin{array}{l}\text { LNCaP, } \\
\text { 22Rm1, DU145 and PC3 cells }\end{array}$ & $1 \mathrm{mM}$ & inhibiting proliferation & $\begin{array}{l}\text { resynchronizing dysregulated } \\
\text { circadian rhythm circuitry }\end{array}$ & {$[100]$} \\
\hline in vivo & nude rats & $\begin{array}{l}\text { amplified by } \\
\text { day time blue } \\
\text { light }\end{array}$ & 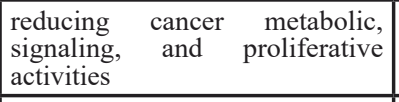 & inhibiting Warburg effect & {$[101]$} \\
\hline in vivo & mice & $4 \mathrm{nM}$ & inhibiting tumor growth & decreasing angiogenesis & {$[102]$} \\
\hline in vivo & nude rats & $\begin{array}{l}\text { human } \\
\text { melatonin-rich } \\
\text { blood }(>100 \\
\text { pg/mL) }\end{array}$ & $\begin{array}{l}\text { dampening signal transduction, } \\
\text { metabolic and growth activity in } \\
\text { cancer xenografts }\end{array}$ & $\begin{array}{l}\text { melatonin MT1 receptor-mediated } \\
\text { mechanism }\end{array}$ & {$[103]$} \\
\hline in vivo & mice & $\begin{array}{l}10 \text { and } 20 \mathrm{mg} / \mathrm{L} \\
\text { in tap water }\end{array}$ & inhibiting cancer tumorigenesis & suppressing Sirt1 activity & [98] \\
\hline
\end{tabular}




\begin{tabular}{|c|c|c|c|c|c|}
\hline in vitro & OVCAR-429 and PA- 1 cells & $\begin{array}{l}400,600, \text { and } \\
800 \mu \mathrm{M}\end{array}$ & inhibition on tumor growth & $\begin{array}{l}\text { delay of } G_{1} / S \text { via down-regulation of } \\
\text { CDK2 } 2 \text { and } 4\end{array}$ & {$[106]$} \\
\hline in vivo & rats & $200 \mu \mathrm{g} / 100 \mathrm{~g}$ & $\begin{array}{l}\text { reducing tumor masses and } \\
\text { incidence of adenocarcinomas }\end{array}$ & NA & [108] \\
\hline in vivo & rats & $200 \mu \mathrm{g} / 100 \mathrm{~g}$ & $\begin{array}{l}\text { reducing tumor masses and } \\
\text { inducing apoptosis }\end{array}$ & $\begin{array}{l}\text { upregulation of p53, BAX, and } \\
\text { cleaved caspase-3, and enhancement } \\
\text { of DNA fragmentation }\end{array}$ & [109] \\
\hline in vivo & rats & $200 \mu \mathrm{g} / 100 \mathrm{~g}$ & reducing tumor volume & $\begin{array}{lcr}\text { attenuating } \begin{array}{c}\text { the } \\
\text { MyD88- } \\
\text { Myd } \\
\text { signaling pathways }\end{array} & \\
\end{array}$ & {$[110]$} \\
\hline in vivo & rats & $200 \mu \mathrm{g} / 100 \mathrm{~g}$ & reducing tumor masses & $\begin{array}{lccc}\text { attenuating } & \text { Her-2, } & \text { p38 } & \text { MAPK, } \\
\text { p-AKT, and } & \text { mTOR Levels }\end{array}$ & {$[112]$} \\
\hline \multicolumn{6}{|c|}{ Cervical Cancer } \\
\hline in vivo & nude rats & $500 \mathrm{pM}$ & inhibiting tumor growth & $\begin{array}{l}\text { inhibiting aerobic glycolysis and fatty } \\
\text { acid metabolic signaling }\end{array}$ & {$[115]$} \\
\hline in vivo & nude rats & $500 \mathrm{pM}$ & $\begin{array}{l}\text { suppressing tumor metabolism } \\
\text { and proliferation }\end{array}$ & $\begin{array}{l}\text { inhibition of linoleic acid transport } \\
\text { and 13-HODE production }\end{array}$ & [116] \\
\hline
\end{tabular}

NA stands for not available.

\section{In vivo studies}

A study using female athymic nude mice reported that melatonin could control metastatic breast cancer through decreasing ROCK-1 expression [81]. In addition, melatonin treatment on nude mice with breast cancer xenografts reduced tumor size and cell proliferation compared to control animals, along with a decrease in expression of VEGF receptor 2 and micro-vessel density, indicating the inhibition of angiogenesis [82]. LAN is a problem co-distributed with breast cancer prevalence worldwide [83]. A study documented LAN's positive effect on breast tumors growth rate, and melatonin could reverse the effect via global DNA methylation [83]. Moreover, another study elucidated the association between LAN-induced circadian disruption and the increased breast cancer risk: LAN disrupted the circadian rhythm of glycogen synthase kinase $3 \beta$ (GSK3 $\beta$ ) through perturbation of the nocturnal surge of melatonin, and melatonin activated GSK3 $\beta$ via inhibiting the serinethreonine kinase Akt phosphorylation and inducing $\beta$-catenin degradation and inhibiting EMT [84].

Several studies reported the synergetic effect of melatonin with other anticancer agents on breast cancer. Melatonin co-administration significantly augmented the pro-differentiating, antiproliferative and immunomodulatory activities presented by Lactobacillus plantarum LS/07 and inulin [85]. In addition, combined treatment of melatonin with Propionibacterium acnes on Balb/C mice transplanted with EMT6/P cell line could inhibit metastasis of cancer cells to other organs, induce apoptosis, reduce angiogenesis, and stimulate strong Th1-type cytokine antitumor immune response [86]. Another study reported melatonin's enhancing effect on the sensitivity of breast tumor to adriamycin [87]. Furthermore, melatonin could potentiate the antitumor effect of pravastatin in rats with mammary gland carcinoma, as shown by decreased tumor frequency by $69 \%$ and lengthened tumor latency by nine days compared with control animals [88]. Additionally, doxorubicin resistance and tamoxifen resistance in breast cancer were caused by LAN-induced disruption of circadian melatonin signal, and melatonin could inhibit tumor metabolism and circadian-regulated kinase to reestablish the sensitivity of breast tumors to doxorubicin [89] and tamoxifen [90].

Collectively, melatonin has exhibited inhibitory effect on both ER-positive and ER-negative breast cancers. Melatonin's anti-breast cancer effect was not only mediated by its interaction with both the estrogen receptors and the melatonin receptors, but also through activating various receptor-independent and estrogenindependent signaling pathways. Given the wide spectrum of melatonin's action on breast cancer, coupled with its low toxicity, it could be considered as a potential therapeutic choice for prevention and treatment of breast cancer.

\section{Prostate cancer}

Prostate cancer is the second most frequently occurred cancer and the fifth leading cause of cancer mortality in men [91]. It was found that melatonin at pharmacological concentrations could inhibit cell growth of both androgen-dependent and androgen-independent prostate cancer [92], through various mechanisms.

\section{In vitro studies}

Melatonin significantly suppressed the expression of angiogenesis-related proteins HIF- $1 \alpha$, HIF- $2 \alpha$ and VEGF at mRNA level of PC-3 cells under hypoxia, and upregulation of miRNA3195 and miRNA374b could mediate this anti-angiogenic property of melatonin [93]. Furthermore, melatonin presented anti-proliferative effects on prostate cancer cell lines, LNCaP and 22Rv1, and the mechanism might involve inactivation of NF$\kappa \mathrm{B}$, via melatonin MT1 receptor-induced dual activation of $\left(\mathrm{G} \alpha_{\mathrm{s}}\right)$ /protein kinase A (PKA) and $\left(\mathrm{G} \alpha_{\mathrm{q}}\right) /$ protein kinase $\mathrm{C}(\mathrm{PKC})$, causing transcriptional upregulation of $\mathrm{p} 27^{\mathrm{Kip} 1}$. The mechanism also involved downregulation of activated AR signaling via PKC stimulation [94, 95]. Another study documented that melatonin suppressed 
Table 3: The in vitro and in vivo activities of melatonin on hormone-independent cancers

\begin{tabular}{|c|c|c|c|c|c|}
\hline Study Type & Subjects & Dose & Main Effect & Possible Mechanisms & Ref. \\
\hline \multicolumn{6}{|l|}{ Oral Cancer } \\
\hline in vitro & $\begin{array}{l}\text { HSC-3, OECM- } \\
1 \text { cells }\end{array}$ & $0.5,1 \mathrm{mM}$ & anti-metastatic effect & $\begin{array}{l}\text { attenuation of MMP-9 expression } \\
\text { and activity mediated by decreasing } \\
\text { histone acetylation }\end{array}$ & [121] \\
\hline in vitro & SCC9 cells & $1 \mathrm{mM}$ & decreasing cell viabilities & $\begin{array}{l}\text { inhibiting the expression of } H I F-1 \alpha \text {, } \\
V E G F \text {, and } R O C K-1 \text { genes }\end{array}$ & [122] \\
\hline \multicolumn{6}{|l|}{ Liver Cancer } \\
\hline in vitro & HepG2 cells & $1 \mathrm{mM}$ & $\begin{array}{l}\text { modulating motility and } \\
\text { invasiveness }\end{array}$ & $\begin{array}{l}\text { upregulation of TIMP-1 and } \\
\text { attenuation of MMP-9 via NF- } \kappa \mathrm{B} \\
\text { signaling pathway inhibition }\end{array}$ & {$[126]$} \\
\hline in vitro & HepG2 cells & $1 \mathrm{mM}$ & anti-angiogenesis activity & $\begin{array}{l}\text { interfering with transcriptional } \\
\text { activation of VEGF, via Hifl } \alpha \text { and } \\
\text { STAT3 }\end{array}$ & [127] \\
\hline in vitro & $\begin{array}{l}\text { HepG2, } \\
\text { SMMC-7721 } \\
\text { cells }\end{array}$ & $\begin{array}{l}10^{-9}, \quad 10^{-7} \\
10^{-5}, 10^{-3} \mathrm{M}\end{array}$ & overcoming apoptosis resistance & $\begin{array}{l}\text { suppressing survivin and XIAP via the } \\
\text { COX-2/PI3K/AKT pathway }\end{array}$ & [128] \\
\hline in vitro & HepG2 cells & \begin{tabular}{|l|}
50 to 2000 \\
$\mu \mathrm{M}$
\end{tabular} & pro-apoptotic effect & regulation of Bim by FoxO3a & [129] \\
\hline in vitro & HepG2 cells & $\begin{array}{l}1000 \text { and } \\
2500 \mu \mathrm{M}\end{array}$ & inhibiting proliferation & $\begin{array}{l}\text { modulation of MT1 membrane } \\
\text { receptor and cAMP and ERK } \\
\text { activation }\end{array}$ & [130] \\
\hline in vivo & HepG2 cells & $\begin{array}{l}10^{-9}, \quad 10^{-7} \\
10^{-5}, 10^{-3} \mathrm{M}\end{array}$ & $\begin{array}{l}\text { sensitizing cancer cells to ER } \\
\text { stress-induced apoptosis }\end{array}$ & $\begin{array}{l}\text { downregulating the } \mathrm{COX}-2 \\
\text { expression and the } \mathrm{Bcl}-2 / \mathrm{Bax} \text { ratio, } \\
\text { elevating level of } \mathrm{CHOP}\end{array}$ & [131] \\
\hline in vivo & mice & $0.5 \mathrm{mg} / \mathrm{kg}$ & $\begin{array}{l}\text { reversing the circadian } \\
\begin{array}{ll}\text { clock disturbed by } \\
\text { hepatocarcinogenesis }\end{array} \\
\end{array}$ & NA & [132] \\
\hline in vivo & rats & $1 \mathrm{mg} / \mathrm{kg}$ & attenuating hepatocarcinogenes & activating ER stress & [133] \\
\hline \multicolumn{6}{|l|}{ Renal Cancer } \\
\hline in vitro & $\begin{array}{ll}\text { Caki-1 and } \\
\text { Achn cells }\end{array}$ & $0.5-2 \mathrm{mM}$ & anti-metastatic effect & $\begin{array}{l}\text { suppressing Akt-MAPKs pathway and } \\
\text { NF-אB DNA-binding activity } \\
\end{array}$ & [135] \\
\hline in vitro & Caki cells & \begin{tabular}{|l|}
$0.1,0.5$, or \\
$1 \mathrm{mM}$ \\
\end{tabular} & inducing apoptosis & upregulation of Bim expression & [136] \\
\hline in vitro & Caki cells & $1 \mathrm{mM}$ & $\begin{array}{l}\text { enhancing apoptosis induced by } \\
\text { thapsigargin }\end{array}$ & $\begin{array}{l}\text { ROS-mediated upregulation of } \\
\text { CCAAT-enhancer-binding protein } \\
\text { homologous protein }\end{array}$ & [137] \\
\hline in vitro & Caki cells & $1 \mathrm{mM}$ & $\begin{array}{l}\text { enhancing apoptosis induced by } \\
\text { kahweol }\end{array}$ & $\begin{array}{l}\text { inducing upregulation of p53- } \\
\text { upregulated modulator of apoptosis }\end{array}$ & [138] \\
\hline \multicolumn{6}{|l|}{ Lung Cancer } \\
\hline in vitro & A549 cells & $\begin{array}{|lr|}0.1, & 0.5 \\
0.75, & 1.0 \\
2.5, & 5.0 \\
M M\end{array}$ & $\begin{array}{l}\text { suppressing cell migration and } \\
\text { viability }\end{array}$ & JNK/MAPK Pathway & [143] \\
\hline \multicolumn{6}{|l|}{ Gastric Cancer } \\
\hline in vitro & SGC-7901 cells & $\begin{array}{l}0.01,0.1,1 \\
3 \mathrm{mM}\end{array}$ & $\begin{array}{l}\text { inhibited HIF-1 } \alpha \text { accumulation } \\
\text { and endogenous VEGF } \\
\text { generation }\end{array}$ & $\begin{array}{l}\text { inhibition of melatonin nuclear } \\
\text { receptor RZR/ROR } \gamma\end{array}$ & [147] \\
\hline in vitro & AGS cells & $\begin{array}{l}0.25,0.5,1 \\
2,4 \mathrm{mM}\end{array}$ & $\begin{array}{l}\text { inhibiting cell viability, clone } \\
\text { formation, cell migration } \\
\text { and invasion, and inducing } \\
\text { apoptosis }\end{array}$ & $\begin{array}{l}\text { activation of JNK and P38 MAPK and } \\
\text { the suppression of NF-kB }\end{array}$ & [149] \\
\hline in vitro & SGC-7901 cells & $10^{-9}-10^{-3} \mathrm{M}$ & $\begin{array}{l}\text { inhibiting cell viability, clone } \\
\text { formation, cell migration, and } \\
\text { promoting apoptosis }\end{array}$ & NA & {$[150]$} \\
\hline in vitro & $\begin{array}{l}\text { murine } \mathrm{MFC} \\
\text { cell }\end{array}$ & $4 \mathrm{mM}$ & inhibiting cancer growth & $\begin{array}{l}\text { increase of } \mathrm{p} 21 \text { and } \mathrm{Bax} \text { and decrease } \\
\text { of Bcl-2 mediated by membranous } \\
\text { melatonin receptors }\end{array}$ & [151] \\
\hline in vitro & SGC-7901 cells & $10^{-4} \mathrm{M}$ & inducing cell differentiation & 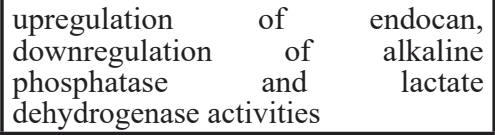 & [153] \\
\hline
\end{tabular}




\begin{tabular}{|c|c|c|c|c|c|}
\hline in vitro & $\begin{array}{l}\text { murine } \mathrm{MFC} \\
\text { cell }\end{array}$ & $\begin{array}{l}2,4,6,8,10 \\
\mathrm{mM}\end{array}$ & $\begin{array}{l}\text { promoting apoptosis and } \\
\text { inducing cell cycle arrest at the } \\
\mathrm{G}_{2} / \mathrm{M} \text { phase } \\
\end{array}$ & \multirow{2}{*}{$\begin{array}{l}\text { downregulation of } \mathrm{CD} 4^{+} \mathrm{CD} 25^{+} \text {cells } \\
\text { and its Forkhead box p3 expression }\end{array}$} & \multirow[t]{2}{*}[152]{} \\
\hline in vivo & mice & $\begin{array}{l}25,50,100 \\
\mathrm{mg} / \mathrm{kg}\end{array}$ & reducing tumor tissue & & \\
\hline in vitro & SGC-7901 cells & $3 \mathrm{mM}$ & inhibiting angiogenesis & \multirow[b]{2}{*}{$\begin{array}{l}\text { suppressing RZR/ROR } \gamma, \text { SENP1, } \\
\text { HIF-1 } \alpha \text {, and VEGF }\end{array}$} & \multirow[b]{2}{*}[148]{} \\
\hline in vivo & nude mice & NA & $\begin{array}{l}\text { reducing tumor volume } \\
\text { and weight and inhibiting } \\
\text { proliferation and angiogenesis } \\
\end{array}$ & & \\
\hline in vivo & BALB/c mice & $\begin{array}{|lr|}5 \mathrm{mg} / \mathrm{kg} / \\
\text { twice/week }\end{array}$ & $\begin{array}{l}\text { impeding tumor growth and } \\
\text { peritoneal dissemination }\end{array}$ & $\begin{array}{l}\text { inducing ER stress and inhibiting } \\
\text { EMT }\end{array}$ & {$[154]$} \\
\hline \multicolumn{6}{|c|}{ Pancreatic Cancer } \\
\hline in vitro & PANC-1 cells & $1 \mathrm{mM}$ & $\begin{array}{l}\text { inhibiting cell proliferation and } \\
\text { angiogenesis }\end{array}$ & decreasing VEGF & {$[158]$} \\
\hline in vitro & AR42J cells & $1 \mathrm{mM}$ & reducing cell viability & $\begin{array}{l}\text { inducing changes of mitochondrial } \\
\text { activity and activating caspase- } 3\end{array}$ & {$[159]$} \\
\hline \multicolumn{6}{|c|}{ Colorectal Cancer } \\
\hline in vitro & HCT 116 cells & $10^{-6} \mathrm{M}$ & \begin{tabular}{|lll}
$\begin{array}{l}\text { decreasing cancer cellular } \\
\text { viability }\end{array}$ & \\
\end{tabular} & increasing ROS level & {$[164]$} \\
\hline in vitro & HT-29 cells & $10^{-6}-10^{-2} \mathrm{M}$ & antiproliferative effect & \begin{tabular}{|lll} 
the antioxidative and anti- \\
inflammatory actions
\end{tabular} & {$[165]$} \\
\hline in vitro & LoVo cells & $\begin{array}{l}10^{-4}, 10^{-3} \\
10^{-2}, 10^{-1}, 1 \\
2 \mathrm{mM}\end{array}$ & $\begin{array}{l}\text { suppressing cell proliferation } \\
\text { and inducing apoptosis }\end{array}$ & $\begin{array}{l}\text { HDAC4 nuclear import mediated by } \\
\text { CaMKII inactivation }\end{array}$ & {$[166]$} \\
\hline in vitro & $\begin{array}{l}\text { Caco-2 and } \mathrm{T} 84 \\
\text { cells }\end{array}$ & \begin{tabular}{|lc}
0.1, & 0.25 \\
$0.5,1 \mathrm{mM}$
\end{tabular} & $\begin{array}{l}\text { inhibiting tumor growth and } \\
\text { progression }\end{array}$ & repressing the activation of ET-1 & {$[168]$} \\
\hline in vitro & Caco- 2 cells & $\begin{array}{|ll|}1.56, & 0.78 \\
\mu \mathrm{g} / \mathrm{mL}\end{array}$ & $\begin{array}{l}\text { inducing morphological } \\
\text { changes in cancer cell }\end{array}$ & generation of ROS & {$[169]$} \\
\hline in vitro & HCT116 cells & $10 \mu \mathrm{M}$ & $\begin{array}{l}\text { activating cell death programs } \\
\text { early }\end{array}$ & inducing $\mathrm{G}_{1}$-phase arrest & {$[170]$} \\
\hline in vivo & mice & $1 \mathrm{mg} / \mathrm{kg}$ bw & $\begin{array}{l}\text { inhibiting the progression } \\
\text { of colitis-associated colon } \\
\text { carcinogenesis }\end{array}$ & $\begin{array}{l}\text { preventing the process of autophagy, } \\
\text { alleviating the level of several } \\
\text { inflammatory markers, and } \\
\text { modulating Nrf } 2 \text { signaling pathway }\end{array}$ & {$[173]$} \\
\hline in vivo & rats & $10 \mathrm{mg} / \mathrm{kg}$ & $\begin{array}{l}\text { controlling the preneoplastic } \\
\text { patterns }\end{array}$ & \begin{tabular}{|l}
$\begin{array}{l}\text { controlling the dysplastic ACF } \\
\text { development }\end{array}$ \\
\end{tabular} & {$[175]$} \\
\hline \multicolumn{6}{|c|}{ Melanoma } \\
\hline in vitro & B16 cells & $10^{-4}-10^{-2} \mathrm{M}$ & reducing cell viability & promoting ROS production & {$[178]$} \\
\hline \multicolumn{6}{|c|}{ Prolactinoma } \\
\hline in vitro & $\begin{array}{l}\text { prolactinoma } \\
\text { cells }\end{array}$ & $10^{-5}-10^{-3} \mathrm{M}$ & \multirow{2}{*}{ inducing apoptosis } & \multirow{2}{*}{$\begin{array}{l}\text { repressing activities of mitochondrial } \\
\text { respiratory complexes and production } \\
\text { of ATP }\end{array}$} & \multirow{2}{*}{ [179] } \\
\hline in vivo & rats & \begin{tabular}{|l|}
0.25 or 0.50 \\
$\mathrm{mg} / \mathrm{d}$
\end{tabular} & & & \\
\hline \multicolumn{6}{|c|}{ Leiomyosarcoma } \\
\hline in vitro & $\begin{array}{l}\text { SK-LMS-1 } \\
\text { cells }\end{array}$ & $\begin{array}{|ll|}100 & \mathrm{nM}-1 \\
\mathrm{pM} & \\
\end{array}$ & $\begin{array}{l}\text { repressing cell proliferation and } \\
\text { cell invasion }\end{array}$ & \multirow{2}{*}{$\begin{array}{l}\text { suppression of aerobic glycolysis and } \\
\text { survival signaling }\end{array}$} & \multirow[b]{2}{*}[180]{} \\
\hline in vivo & nude rats & \begin{tabular}{|l|} 
human \\
melatonin- \\
rich blood \\
\end{tabular} & $\begin{array}{l}\text { inhibiting tumor proliferative } \\
\text { activity }\end{array}$ & & \\
\hline \multicolumn{6}{|c|}{ Alveolar Rhabdomyosarcoma } \\
\hline in vitro & RH30 cells & $1,2 \mathrm{mM}$ & inducing cell death & NA & {$[181]$} \\
\hline \multicolumn{6}{|c|}{ Ehrlich Ascites Carcinoma } \\
\hline in vivo & mice & $5,10 \mathrm{mg} / \mathrm{kg}$ & oncostatic and cytotoxic activity & NA & {$[182]$} \\
\hline \multicolumn{6}{|c|}{ Leukaemia } \\
\hline in vivo & \begin{tabular}{|lr} 
Rats & injected \\
with & HL-60 \\
cells & \\
\end{tabular} & $\begin{array}{l}20 \mu \mathrm{g} / \mathrm{mL} \text { in } \\
\text { tap water }\end{array}$ & $\begin{array}{l}\text { anti-apoptotic effects on } \\
\text { lymphocytes and neutrophils }\end{array}$ & inhibiting caspase- 3 and -9 activity & {$[183]$} \\
\hline in vitro & $\begin{array}{l}\text { human } \\
\text { malignant } \\
\text { haematological } \\
\text { cell }\end{array}$ & $1 \mathrm{mM}$ & inducing cell death & $\begin{array}{l}\text { activation of the extrinsic pathway of } \\
\text { apoptosis }\end{array}$ & {$[184]$} \\
\hline
\end{tabular}

NA stand for not available. 
Table 4: The synergetic effect of melatonin with other anticancer drugs or radiotherapy

\begin{tabular}{|c|c|c|c|c|}
\hline Cancer Category & Study Type & Treatment & Main Effect & Ref. \\
\hline breast cancer & in vitro & $\begin{array}{l}\text { melatonin }(0.3 \quad \mathrm{mM}) \\
\text { doxorubicin }(0.5 \text { or } 1 \mu \mathrm{M})\end{array}$ & inducing apoptosis and cell death by activating TRPV1 & {$[74]$} \\
\hline breast cancer & in vitro & $\begin{array}{l}\text { melatonin }(0.5-5 \mu \mathrm{M})+\text { arsenic } \\
\text { trioxide }(0.5-5 \mu \mathrm{M})\end{array}$ & $\begin{array}{l}\text { enhancing the apoptotic cell death by generation of ROS, } \\
\text { upregulation of Redd } 1 \text { expression, and activation of the p } 38 / \mathrm{JNK} \\
\text { pathways }\end{array}$ & {$[75]$} \\
\hline breast cancer & in vitro & $\begin{array}{l}\text { melatonin }(3 \mathrm{mM})+\text { puromycin } \\
(1 \mu \mathrm{M})\end{array}$ & $\begin{array}{l}\text { inhibiting cancer cell viability by inhibiting } 45 \mathrm{~S} \text { pre-rRNA and } \\
\text { XPO1 and downregulating IPO7, procaspase } 3 \text { and Bcl-xL }\end{array}$ & {$[76]$} \\
\hline breast cancer & in vitro & $\begin{array}{l}\text { melatonin }(100 \mu \mathrm{M})+\text { all- } \\
\text { trans retinoic acid }(1 \mu \mathrm{M})+ \\
\text { Somatostatin }(1 \mu \mathrm{M})\end{array}$ & enhancing the growth inhibitory effect & {$[77]$} \\
\hline breast cancer & in vitro & $\begin{array}{l}\text { melatonin }(1 \mathrm{nM})+\text { vitamin } \mathrm{D}_{3} \\
(1 \mathrm{nM})\end{array}$ & $\begin{array}{l}\text { inhibiting cell proliferation through a TGF } \beta \text {-1-dependent } \\
\text { mechanism }\end{array}$ & {$[78]$} \\
\hline breast cancer & in vitro & $\begin{array}{l}\text { melatonin }(1 \mathrm{nM}-1 \mathrm{mM})+ \\
\text { ionizing radiation }(0-12 \mathrm{~Gy})\end{array}$ & $\begin{array}{l}\text { sensitizing cancer cells to radiation by downregulating proteins } \\
\text { involved in double-strand DNA break repair }\end{array}$ & {$[79]$} \\
\hline breast cancer & in vitro & $\begin{array}{l}\text { melatonin }(1 \mathrm{nM}-1 \mathrm{mM})+ \\
\text { radiation }(8 \mathrm{~Gy})\end{array}$ & enhancing radiosensitivity of cancer cell by modulation on p53 & {$[80]$} \\
\hline breast cancer & in vivo & $\begin{array}{l}\text { melatonin }(20 \mathrm{mg} / \mathrm{L})+\mathrm{L} \\
\text { plantarum } \mathrm{LS} / 07\left(8.4{ }^{\prime}\right. \\
\text { c.f.u. })+ \text { inulin }(20 \mathrm{~g} / \mathrm{kg})\end{array}$ & $\begin{array}{l}\text { augmenting the pro-differentiating, antiproliferative activities via } \\
\text { enhancing immunomodulatory action }\end{array}$ & {$[85]$} \\
\hline breast cancer & in vivo & $\begin{array}{l}\text { melatonin }(10 \mathrm{mg} / \mathrm{kg})+P . \\
\text { acnes }\left(1^{\prime} 10^{6} \text { cells }\right)\end{array}$ & $\begin{array}{l}\text { reducing angiogenesis, inhibiting metastasis, inducing apoptosis by } \\
\text { stimulating strong Th1-type cytokine antitumor immune response }\end{array}$ & {$[86]$} \\
\hline breast cancer & in vivo & melatonin + adriamycin & sensitizing tumor to adriamycin & [87] \\
\hline breast cancer & in vivo & $\begin{array}{l}\text { melatonin }(20 \mathrm{~g} / \mathrm{mL})+ \\
\text { pravastatin }(100 \mathrm{mg} / \mathrm{kg})\end{array}$ & enhancing the anti-tumor effect of pravastatin & {$[88]$} \\
\hline breast cancer & in vivo & $\begin{array}{l}\text { melatonin }(0.1 \mu \mathrm{g} / \mathrm{mL})+ \\
\text { doxorubicin }(6 \mathrm{mg} / \mathrm{kg})\end{array}$ & $\begin{array}{l}\text { inhibiting tumor metabolism, reestablishing the sensitivity of breast } \\
\text { tumors to doxorubicin and driving tumor regression by inhibition on } \\
\text { circadian-regulated kinase }\end{array}$ & {$[89]$} \\
\hline breast cancer & in vivo & $\begin{array}{l}\text { melatonin }(0.1 \mu \mathrm{g} / \mathrm{mL})+ \\
\text { tamoxifen }(80 \mathrm{mg} / \mathrm{kg})\end{array}$ & $\begin{array}{l}\text { inhibiting tumor metabolism, reestablishing the sensitivity of breast } \\
\text { tumors to tamoxifen and driving tumor regression by inhibition on } \\
\text { circadian-regulated kinase }\end{array}$ & {$[90]$} \\
\hline ovarian cancer & in vitro & $\begin{array}{l}\text { melatonin }(0-2 \mathrm{mM})+\text { cisplatin } \\
(80 \mu \mathrm{M})\end{array}$ & $\begin{array}{l}\text { enhancing cisplatin-induced apoptosis by inactivation of ERK/ } \\
\text { p90RSK/HSP27 cascade }\end{array}$ & [107] \\
\hline cervical cancer & in vitro & $\begin{array}{l}\text { melatonin }(1 \mathrm{mM})+\text { cisplatin } \\
(20 \mu \mathrm{M})\end{array}$ & $\begin{array}{l}\text { reducing cell viability and enhancing cytotoxicity of cisplatin by } \\
\text { ROS overproduction and enlarged DNA fragmentation }\end{array}$ & {$[114]$} \\
\hline endometrial cancer & in vivo & \begin{tabular}{lll|}
$\begin{array}{l}\text { melatonin } \\
\text { estrogen }\end{array}$ & $(25 \mu \mathrm{g} / \mathrm{mL}) \quad+$ \\
\end{tabular} & $\begin{array}{l}\text { decreasing endometrial proliferation and preventing the appearance } \\
\text { of cellular atypia }\end{array}$ & {$[119]$} \\
\hline lung cancer & in vitro & $\begin{array}{l}\text { melatonin }(0.1 \mathrm{mM})+\mathrm{UV} \\
\text { irradiation }\end{array}$ & enhancing apoptosis induced by UV irradiation & {$[142]$} \\
\hline lung cancer & in vitro & $\begin{array}{l}\text { melatonin }(1 \mathrm{mM})+\text { berberine } \\
(100 \mu \mathrm{M})\end{array}$ & $\begin{array}{l}\text { sensitizing cancer cells to berberine via activation of } \\
\text { caspase/Cyto } \mathrm{C} \text { and inhibition of AP-2 } \beta / \mathrm{hTERT}, \mathrm{NF}-\kappa \mathrm{B} / \mathrm{COX}-2 \\
\text { and Akt/ERK signaling pathways }\end{array}$ & {$[140]$} \\
\hline lung cancer & in vitro & $\begin{array}{l}\text { melatonin }(1 \mathrm{mM})+\text { gefitinib } \\
(1 \mu \mathrm{M})\end{array}$ & $\begin{array}{l}\text { downregulating EGFR phosphorylation and inducing apoptosis by } \\
\text { sensitizing TKI-resistant cell to gefitinib }\end{array}$ & [144] \\
\hline \multirow{2}{*}{ pancreatic cancer } & in vitro & \multirow{2}{*}{$\begin{array}{l}\text { melatonin }(1.5 \mathrm{mM})+ \\
\text { gemcitabine }(20 \mathrm{mM})\end{array}$} & \multirow{2}{*}{$\begin{array}{l}\text { inducing apoptosis and necrosis by modulation of } \mathrm{Bcl}-2 / \mathrm{Bax} \\
\text { balance }\end{array}$} & \multirow{2}{*}[160]{} \\
\hline & in vivo & & & \\
\hline pancreatic cancer & in vitro & $\begin{array}{|lrr|}\text { melatonin }(1 & \mathrm{mM}) & + \\
5 \text {-fluorouracil } & (1 & \mathrm{mM}) \\
\text { or cisplatin }(20 & \mu \mathrm{M}) & \text { or } \\
\text { doxorubicin }(1 \mu \mathrm{M}) & & \\
\end{array}$ & $\begin{array}{l}\text { enhancing cytotoxicity and apoptosis by increasing intracellular } \\
\text { ROS production and enhancing mitochondrial membrane } \\
\text { depolarization }\end{array}$ & {$[161]$} \\
\hline pancreatic cancer & in vivo & $\begin{array}{l}\text { melatonin }(20 \mu \mathrm{g} / \mathrm{mL})+ \\
\text { capecitabine }(50 \mathrm{mg} / \mathrm{d})\end{array}$ & $\begin{array}{l}\text { improving antitumor activity by decreasing lipoperoxide levels and } \\
\text { increasing antioxidant activity }\end{array}$ & [162] \\
\hline colorectal cancer & in vitro & $\begin{array}{l}\text { melatonin }(1.0 \mathrm{mM}))+ \text { ursolic } \\
\text { acid }(20 \mu \mathrm{M})\end{array}$ & $\begin{array}{l}\text { enhancing antiproliferative and pro-apoptotic activities by } \\
\text { regulation of cytochrome c/caspase, MMP9/COX-2, and p300/NF- } \\
\kappa \mathrm{B} \text { signaling pathways }\end{array}$ & {$[172]$} \\
\hline melanoma & in vitro & $\begin{array}{l}\text { melatonin }(0.1-1.0 \mu \mathrm{mM}) \\
+ \text { thapsigargin }(1 \mu \mathrm{M}) \text { or } \\
\text { tunicamycin }(5 \mu \mathrm{g} / \mathrm{mL})\end{array}$ & $\begin{array}{l}\text { decreasing cell viability via regulation of the } \mathrm{PI} 3 \mathrm{~K} / \mathrm{Akt} / \mathrm{mTOR} \\
\text { pathway }\end{array}$ & {$[176]$} \\
\hline melanoma & in vitro & $\begin{array}{l}\text { melatonin }(0.1-1.0 \mathrm{mM})+ \\
\text { fisetin }(20 \mu \mathrm{M})\end{array}$ & $\begin{array}{l}\text { enhancing the antitumor activity by inhibition of COX-2/iNOS and } \\
\text { NF- } \mathrm{KB} / \mathrm{p} 300 \text { signaling pathways }\end{array}$ & {$[177]$} \\
\hline glioblastomas & in vitro & $\begin{array}{l}\text { melatonin }(1 \quad \mathrm{mM}) \\
\text { temozolomide } \\
(0-2 \mathrm{mM}) \text { or doxorubicin }(0-50 \\
\mathrm{mM}) \text { or mitoxantrone }(0-50 \\
\mathrm{mM})\end{array}$ & $\begin{array}{l}\text { inducing a synergistic toxic effect on cancer cell by increasing } \\
\text { methylation of the ABCG2/BCRP promoter }\end{array}$ & [186] \\
\hline Ewing sarcoma & in vitro & $\begin{array}{l}\text { melatonin }(1 \mathrm{mM})+\text { vincristine } \\
(5 \mathrm{nM}) \text { or ifosfamide }(0.5 \mathrm{mM})\end{array}$ & $\begin{array}{l}\text { exerting synergistic antitumor effect by potentiating extrinsic } \\
\text { apoptotic pathway }\end{array}$ & {$[187]$} \\
\hline
\end{tabular}


HIF-1 $\alpha$ accumulation via inactivating sphingosine kinase 1 pathway and scavenging free radicals in hypoxic PC-3 cells, thus melatonin could act as a potent anticancer supplement for prostate cancer therapy [96]. Sirt1 (sirtuin 1) is a $\mathrm{NAD}^{+}$-dependent histone deacetylase and overexpressed in prostate cancer cells [97]. Melatonin significantly suppressed Sirt1 activity in vitro in multiple human prostate cancer cell lines, accompanied by a significant reduction in the proliferative potential of $\mathrm{PCa}$ cells [98]. In addition, melatonin could cause phenotypic changes, mainly neuroendocrine differentiation, thereby sensitizing human prostate cancer cells to apoptosis induced by cytokines, such as TNF- $\alpha$ or TRAIL [99]. Overexpression of Period 2 (Per2) gene could lead to a significant decrease of PCa cell growth and viability, and melatonin treatment could inhibit proliferation of prostate cancer cells by resynchronizing dysregulated circadian rhythm circuitry through upregulating Per2 and Clock genes and downregulating Bmal1 [100].

\section{In vivo studies}

Daytime blue light could increase nocturnal melatonin and then enhance the inhibition on human prostate cancer growth on male nude rats, as shown by decreased tumor growth rates, tumor cAMP levels, aerobic glycolysis (Warburg effect), uptake-metabolism of linoleic acid, and growth signaling activities [101]. In another study, melatonin in LNCaP human prostate cancer cells xenografted mice inhibited the xenograft growth rate by exerting an anti-angiogenesis effect by reducing xenograft microvessel density and expression of Ki67, and elevating expression of HIF-1 $\alpha$ and phosphorylation of Akt. Melatonin also restored the redox imbalance by promoting expression of Nrf2 [102]. Furthermore, human volunteer nighttime-collected, melatonin-rich blood dampened signal transduction, metabolic and growth activity in tissue-isolated PC-3 cancer xenografts, via a melatonin MT1 receptor-mediated mechanism. On the contrary, blood collected from human subjects exposed to LAN exerted an exactly opposite effect via suppression of the nocturnal circadian melatonin signal [103]. Besides, oral administration of melatonin significantly inhibited prostate cancer tumorigenesis as characterized by reduction in prostate and genitourinary weight, serum IGF-1/IGFBP3 ratio, and mRNA and protein levels of PCNA and Ki-67, which were accompanied with a significant reduction in Sirt1 [98].

Collectively, these scientific literatures support the potential application of melatonin in the prevention and treatment of prostate cancer. Especially, melatonin could exert antiproliferative activity on androgen-independent prostate cancer cells (e.g. PC-3 cells), which makes melatonin a clinical choice to postpone the relapse of hormone-refractory or castration-resistant prostate cancer in combination with androgen deprivation therapy.

\section{Ovarian cancer}

Ovarian cancer is one of the leading cause of death among women with genital tract disorders [104]. Although various surgical techniques and chemotherapies have been applied to the treatment of ovarian carcinoma, the prognosis remains poor [105]. In recent years, a few studies have reported the anticancer effect of melatonin on ovarian cancer.

\section{In vitro studies}

Melatonin induced an accumulation of OVCAR-429 and PA-1 ovarian cancer cells in the $\mathrm{G}_{1}$ phase via downregulation of CDK 2 and 4 [106]. Besides, although melatonin alone showed no significant cytotoxicity against SK-OV-3 human ovarian cancer cells, melatonin could synergistically enhance cisplatin-induced apoptosis. The pro-apoptotic effect was through inactivating caspase-3 and promoting cisplatin-mediated inhibition of extracellular signal regulated kinase (ERK), 90-kDa ribosomal S6 kinase (p90RSK) and heat shock protein 27 (HSP27) phosphorylation [107].

\section{In vivo studies}

A group studied the oncostatic effect of melatonin on ovarian cancer using an ethanol-preferring rat model, in which the left ovary was inoculated with ovarian tumor and right ovary was used as the sham-surgery control [108-110]. They found that melatonin could reduce ovarian tumor masses and decrease the incidence of adenocarcinoma in rats [108]. Later, they investigated the apoptosis-promoting effect of melatonin on ovarian cancer. Results showed that absolute and relative tumor masses were significantly reduced after melatonin therapy, regardless of ethanol consumption. Melatonin therapy promoted apoptosis as characterized by upregulation of p53, BAX, and cleaved caspase-3, as well as enhancement of DNA fragmentation [109]. Furthermore, the group found that melatonin attenuated the TLR4-induced MyD88- and TRIF-dependent signaling pathways in rats with ovarian cancer [110]. In addition, epidermal growth factor receptors 2 (Her-2) and 4 (Her-4) were closely related with the progression and metastasis of ovarian cancer [111]. A study found that melatonin could attenuate the Her-2-signaling pathway in the ethanol-preferring rat model, by significantly suppressing the expression of Her2, p38 MAPK, and p-Akt [112].

Collectively, melatonin has shown anticancer effect on ovarian cancer, and the underlying mechanisms include inducing apoptosis and cell cycle arrest, and immunoregulation (toll-like receptors).

\section{Cervical cancer}

Cervical cancer is the second leading cause of female tumor worldwide, and its incidence in developing 
countries is much higher than that in developed countries [113]. The anticancer effect of melatonin on cervical cancer has been reported in a few studies.

\section{In vitro studies}

Melatonin decreased HeLa cell viability, and significantly enhanced the cytotoxic effect of 3 chemotherapeutic agents (cisplatin, 5-fluorouracil, and doxorubicin), as shown by increased caspase-3 activation. Especially, co-treatment of melatonin and cisplatin significantly elevated the ratio of cells entering mitochondrial apoptosis though ROS overproduction, and markedly enlarging DNA fragmentation compared to cisplatin treatment alone [114].

\section{In vivo studies}

Melatonin inhibited growth of HeLa cervical cancer xenografts perfused in situ in nude rats, via inhibiting aerobic glycolysis (Warburg effect) and fatty acid metabolic signaling [115]. Furthermore, melatonin suppressed HeLa cervical adenocarcinoma metabolism and proliferation through inhibition of linoleic acid transport and 13-hydroxyoctadecadienoic acid production via a receptor-mediated signal transduction [116].

Melatonin could reduce cervical cancer cell viability in vitro, and suppress cervical adenocarcinoma metabolism in vivo. More studies are required to fully explain the oncostatic effect of melatonin on cervical cancer and support the clinical application of melatonin.

\section{Endometrial cancer}

Endometrial cancer, like breast cancer, is an estrogen-dependent neoplasm, and its incidence is rapidly increasing worldwide [117, 118]. The effect of melatonin on endometrial cancer was only reported in few studies.

\section{In vivo studies}

Visceral obesity is a risk factor of endometrial cancer, as it is associated with chronic inflammatory process [119]. Ciortea et al. reported that, compared with estrogen replacement treatment, the combinational treatment of melatonin and estrogen in ovariectomized rats was associated with lower body weight, less intraretroperitoneal fat, reduction in endometrial proliferation, and less appearance of cellular atypia. These results indicated that melatonin supplementation might be used in the prophylaxis of endometrial cancer in menopause women [119].

\section{Hormone-independent cancers}

\section{Oral cancer}

Oral cancer is a common type of human head and neck cancers, and most of the cases involve oral squamous cell carcinoma [120]. In several in vitro studies, melatonin has shown noteworthy effect on oral cancer.

In a study, melatonin presented an anti-metastatic effect on oral cancer cell lines (HSC-3 and OECM-1), through attenuation of MMP-9 expression and activity, which was mediated by decreasing histone acetylation [121]. Besides, melatonin could decrease the cell viabilities of SCC9 and SCC25 cell lines (both squamous cell carcinoma of the tongue), and exert an inhibitory effect on the expression of pro-metastatic gene, $R O C K$ 1 , and pro-angiogenic genes, $H I F-1 \alpha$ and $V E G F$ in SCC9 cell line [122].

Collectively, melatonin has shown inhibitory effect on some oral cancer cells, and the underlying mechanisms mainly involved inhibition on metastasis and angiogenesis.

\section{Liver cancer}

Liver cancer is the second most common cause of cancer death globally, and hepatocellular carcinoma (HCC) is the major kind of liver cancer (70\%-80\%), which is one of the most frequent cancers with the highest incidence in developing countries [123, 124]. Surgery remains the most effective treatment for patients with HCC, but it is only suitable to limited cases, thus finding effective chemotherapeutic drug is required [125]. The effects of melatonin on liver cancer have been reported in several studies.

\section{In vitro studies}

A study revealed the underlying mechanism of melatonin's anti-invasive activity in HepG2 liver cancer cells, which was through suppressing MMP-9 gelatinase activity, downregulating MMP-9 gene expression, upregulation of tissue inhibitor of metalloproteinases (TIMP)-1, and depressing NF- $\mathrm{B}$ translocation and transcriptional activity [126]. Furthermore, melatonin also showed anti-angiogenic effects on HepG2 liver cancer cells through interfering with the transcriptional activation of VEGF, reducing Hifl $\alpha$ protein expression and STAT3 activity [127]. Additionally, it's well established that inhibitor of apoptosis proteins (IAPs) play crucial parts in apoptosis resistance, and one study documented that melatonin could overcome apoptosis resistance in human hepatocellular carcinoma by suppressing survivin and XIAP (both are members of IAPs) via the COX-2/PI3K/AKT pathway [128]. Furthermore, melatonin exerted pro-apoptotic effect via upregulating expression of Bcl-2-interacting mediator (Bim) by FoxO3a on HepG2 hepatocarcinoma cells, through activation of the transcription factor FoxO3a and increased its nuclear localization. Meanwhile, the induced apoptosis was not observed in primary human hepatocytes (used as control) [129]. Another study documented that melatonin reduced cell viability and inhibited the proliferation of HepG2 cells, which was modulated by the MT1 membrane receptor. Meanwhile, the decrease of cAMP level and increase of ERK activation induced 
by melatonin were also responsible for the inhibitory effect [130]. Endoplasmic reticulum (ER) stress-mediated cell apoptosis is involved in cancer development and progression. Another study revealed that melatonin could sensitize human hepatoma cells to ER stress-induced apoptosis through downregulating the $\mathrm{COX}-2$ expression and the $\mathrm{Bcl}-2 / \mathrm{Bax}$ ratio, and elevating the levels of $\mathrm{C} / \mathrm{EBP}$ homologous protein (CHOP) [131].

\section{In vivo studies}

In a study, melatonin reversed the alteration caused by $\mathrm{N}$-nitrosodiethylamine-induced liver tumor in liver marker enzymes (ALT, AST), antioxidant levels, and circadian clock disturbance in mice [132]. Another study suggested that melatonin attenuated hepatocarcinogenesis induced by diethylnitrosamine in rats, by activating ER stress and inducing apoptosis [133].

Collectively, melatonin could inhibit the process of hepatocarcinogenesis mainly through the pro-apoptotic (via modulation of COX-2/PI3K/AKT pathway, Bcl-2/ Bax ratio, activation of ER stress), anti-angiogenesis and anti-invasive effects.

\section{Renal cancer}

Renal cancer is highly aggressive and the third most common urologic cancer, which accounts for approximately $3 \%$ of adult cancers with a male predominance (sex ratio 3/1) [134]. The research on melatonin's anticancer effect on renal cancer is summarized.

\section{In vitro studies}

A recent study systematically investigated the antimetastatic effect of melatonin on renal cell carcinoma (RCC) [135]. Melatonin inhibited MMP-9 transactivation and tumor metastasis though inhibiting Akt-MAPKs pathway and NF- $\kappa \mathrm{B}$ DNA-binding activity. Moreover, clinical sample analysis found a higher survival rate in MTNR1A ${ }^{\text {high }} /$ MMP-9 $9^{\text {low }}$ patients than in MTNR1A $\mathrm{A}^{\text {low }}$ MMP-9 $9^{\text {high }}$ patients [135]. Melatonin also induced apoptosis by upregulating the expression of Bim in renal cancer Caki cells, at both transcriptional level and posttranslational level [136]. Furthermore, co-treatment of melatonin $(1 \mathrm{mM})$ and thapsigargin $(50 \mathrm{nM})$ induced more apoptosis in human renal cancer cells than treatment with thapsigargin alone, which was through ROS-mediated upregulation of CCAAT-enhancer-binding protein homologous protein [137]. Co-treatment of melatonin and kahweol induced apoptosis, stimulated DEVDase activity (could reflect caspase-3 activity), and DNA fragmentation of Caki renal cancer cells. The mechanism underlying was elucidated as inducing upregulation of p53-upregulated modulator of apoptosis [138].

Collectively, inducing apoptosis and inhibiting metastasis are the main effects of melatonin on renal cancer cells. Moreover, concomitant melatonin ministration with other therapies might be an effective clinical choice for patients with renal cancer, given that melatonin showed enhancement effect on other anticancer agents.

\section{Lung cancer}

Lung cancer is a leading cause of cancer-related death. For instance, lung cancer is the second most frequent type of cancer in males with approximately 17,330 new cases identified in 2016 in Brazil [139]. Nonsmall-cell lung cancer (NSCLC) is a major form of lung cancer [140], and the published literature have suggested that the disruption of melatonin rhythm could increase the NSCLC incidence [141]. In several studies, melatonin has been reported to be a potential therapeutic strategy for lung cancer, mainly because melatonin showed to enhance the effects of radiotherapy and some anticancer drugs.

\section{In vitro studies}

In a study, it was found that in cell cycle and apoptosis regulator 2 (CCAR2)-deficient cancer cells, melatonin augmented the apoptosis induced by genotoxic stress caused by UV irradiation. The results indicated that melatonin could be a potential supplement to classical antitumor drugs in therapies against CCAR2-deficient cancers [142]. In addition, melatonin significantly suppressed the migration and viability of A549 cells, which might be through downregulation of the expression of osteopontin, myosin light chain kinase, phosphorylation of myosin light chain, and upregulation of the expression of occludin involving JNK/MAPK pathway [143]. A study showed melatonin effectively increased the berberineinduced inhibitions of cell proliferation, migration and apoptosis. The enhancing effect was possibly through activation of caspase/Cyto $\mathrm{C}$ and inhibition of AP-2 $\beta$ / hTERT, NF- $\mathrm{B} / \mathrm{COX}-2$ and Akt/ERK signaling pathways [140]. In addition, the use of EGFR tyrosine kinase inhibitors (TKIs) to treat advanced NSCLC patients has become a standard of care, but NSCLC patients with somatic EGFR mutations, particularly T790M, showed drug resistance to TKIs. Treatment of melatonin with gefitinib (a type of TKI) effectively decreased the viability of H1975 cells containing the T790M somatic mutation, downregulated EGFR phosphorylation, and induced apoptosis compared to treatment with gefitinib or melatonin alone [144].

Judging from the available evidence, melatonin's effect was more significant when it was used as an adjuvant therapy than being used alone for lung cancer. The enhancement of melatonin on the therapeutic effects of gefitinib, berberine and doxorubicin demonstrated its beneficial role in prevention and treatment for lung cancer. 


\section{Gastric cancer}

Gastric cancer is one of the most common forms of cancer worldwide, and causes a mortality rate ranking second among malignant tumors worldwide [145]. It was estimated that there were 951,600 new cases and 723,100 deaths from gastric cancer in 2012 worldwide [146]. Melatonin has been reported to inhibit gastric cancer through various mechanisms in several studies.

\section{In vitro studies}

In a study, melatonin inhibited HIF- $1 \alpha$ accumulation and endogenous VEGF generation through inhibition of RZR/ROR $\gamma$ in hypoxic SGC-7901 cells, thus inhibiting the proliferation of gastric cancer cells [147]. Besides, melatonin inhibited angiogenesis in SGC-7901 gastric cancer cell line as shown by decreased expression of VEGF mRNA and protein and suppressed expression of nuclear receptor RZR/ROR $\gamma$ mRNA and protein [148]. In addition, melatonin was able to inhibit cell viability, clone formation, cell migration and invasion, and induce apoptosis of AGS gastric cancer cell line, through the activation of JNK and P38 MAPK and the suppression of NF- $\mathrm{kB}$. Moreover, melatonin significantly potentiated the anti-tumor effect of cisplatin with low systemic toxicity [149]. Melatonin's inhibitory effects on cell proliferation, colony formation and migration efficiency, and pro-apoptotic effect were also shown on gastric adenocarcinoma cell line SGC7901 [150]. In addition, melatonin inhibited murine foregastric carcinoma (MFC) cell growth in dose- and time-dependent manners, through increase of p21 and Bax and decrease of Bcl-2, which was mediated by membranous melatonin receptors [151]. In another study, melatonin promoted apoptosis dosedependently and induced cell cycle arrest at the $\mathrm{G}_{2} / \mathrm{M}$ phase in MFC cells, and the mechanism was associated with downregulation of $\mathrm{CD}^{+}$and $\mathrm{CD} 25^{+}$regulatory $\mathrm{T}$ cells and its Forkhead box p3 (Foxp3) expression in the tumor tissue [152]. Additionally, gastric cancer cells SGC7901 cultured with melatonin showed more differentiated morphologic phenotype as compared with untreated cells, accompanied with upregulation of gene expression of endocan and downregulation of alkaline phosphatase and lactate dehydrogenase activities, two enzymes that promote de-differentiation in gastric tissue [153].

\section{In vivo studies}

A study found melatonin-induced $\mathrm{C} / \mathrm{EBP} \beta$ and NF- $\kappa \mathrm{B}$ suppression could impede both gastric tumor growth and peritoneal dissemination via inhibiting EMT and inducing ER stress [154]. In addition, melatonin reduced the tumor volume and weight of tumor in gastric tumor-bearing nude mice, and inhibited proliferation and angiogenesis through suppressing the expression of RZR/ ROR $\gamma$, Sentrin-specific protease 1 (SENP1), HIF-1 $\alpha$, and
VEGF [148]. In another study, mice were inoculated with MFC cells and treated with different doses of melatonin $(0,25,50$, and $100 \mathrm{mg} / \mathrm{kg}$, i.p.). Results showed that tumor tissue was reduced and Tregs numbers and Foxp3 expression in the tumor tissue were inhibited by melatonin treatment [152].

In general, melatonin has shown noteworthy inhibitory effect on the growth of gastric cancer cells. The underlying mechanisms mainly included inhibiting angiogenesis, promoting apoptosis and immunoregulation effect.

\section{Pancreatic cancer}

Pancreatic cancer is a highly lethal disease with a relatively low 5 -year survival rate $[155,156]$. It responds poorly to radiotherapy and chemotherapy because the tumor cells are resistant to apoptosis [157].

\section{In vitro studies}

In a study, $1 \mathrm{mM}$ concentration of melatonin exhibited high inhibitory effect on cellular proliferation of pancreatic carcinoma cells (PANC-1), along with a significantly decrease in VEGF [158]. Besides, melatonin reduced viability of pancreatic tumor AR42J cells through inducing changes of mitochondrial activity and activating caspase-3 [159]. Furthermore, melatonin alone or combined with gemicitabine exhibited growth inhibition on pancreatic cancer cell line SW-1990. The mechanism was through downregulation of $\mathrm{Bcl}-2$ expression and upregulation of Bax expression [160]. Furthermore, melatonin enhanced cytotoxicity and apoptosis induced by 3 chemotherapeutic agents (5-fluorouracil, cisplatin and doxorubicin) in AR42J pancreatic cancer cells in vitro [161]. The enhancing effect was characterized as elevated intracellular ROS production, enhanced mitochondrial membrane depolarization, and increased the population of apoptotic cells.

\section{In vivo studies}

In a study, melatonin alone or combined with gemicitabine inhibited the growth of transplanted tumors in nude mice, through its pro-apoptotic and pro-necrotic effect via downregulation of Bcl-2 expression and upregulation of Bax expression [160]. Besides, melatonin could improve antitumor activity of capecitabine in pancreatic cancer [162]. Results showed that in group of treatment with capecitabine and melatonin alone, pancreatic adenocarcinoma induced by N-nitrosobis(2oxopropyl)amine was observed in $66 \%$ and $33 \%$ of the animals, respectively. However, in the group treated with combination of capecitabine and melatonin, only $10 \%$ of animals showed pancreatic adenocarcinoma.

In general, melatonin has shown inhibition on the growth of some pancreatic cancer cells. Furthermore, melatonin could enhance the efficacy of other anticancer 
agents on pancreatic cancer, especially gemcitabine, which is currently the standard chemotherapy for pancreatic cancer.

\section{Colorectal cancer}

Colorectal cancer is one of the major causes responsible for cancer death worldwide [163], and in several studies, melatonin has shown anticancer potency for various colorectal cancers.

\section{In vitro studies}

A study showed that melatonin increased ROS levels and decreased cellular viability of HCT 116 human colorectal carcinoma cells [164]. Melatonin's oncostatic effect was also associated with its antioxidative and anti-inflammatory activities, counteracting the oxidative status and inhibiting the nitric oxide production in cultured colon cancer cells [165]. In another study, cell proliferation was suppressed significantly and apoptosis was induced by melatonin on colorectal cancer LoVo cell at pharmacological concentrations in a dosedependent manner [166]. The mechanism underlying was explained as through histone deacetylase 4 (HDAC4) nuclear import and subsequent $\mathrm{H} 3$ deacetylation via the inactivation of $\mathrm{Ca}^{2+} /$ calmodulin-dependent protein kinase II $\alpha$ (CaMKII). Endothelin-1 (ET-1) is a peptide, which acts as a protector of carcinoma cells from apoptosis and promoter of angiogenesis [167]. A study showed that melatonin might inhibit tumor growth and progression of colon carcinoma via repressing the activation of ET-1 [168]. Another study investigated the ultrastructural aspect of melatonin cytotoxicity on Caco-2 human colon adenocarcinoma cell line. Results showed that ultrastructurally, Caco-2 cells showed morphological changes in melatonin treatments at 1.56 and $0.78 \mu \mathrm{g} / \mathrm{mL}$ with characteristics of cell degeneration as shown by the absence of microvilli, mitochondrial degeneration, presence of numerous vacuoles, and nuclear fragmentation, indicating that melatonin could promote cytotoxicity in Caco-2 cells [169]. Furthermore, a study determined the interaction between cell death and cellular senescence in human colorectal cancer cells induced by melatonin [170]. Melatonin treatment of $10 \mu \mathrm{M}$ activated cell death programs and induced $\mathrm{G}_{1}$-phase arrest at the advanced phase of cancer cells, and induced insignificant deleterious effects on neonatal cardiomyocytes, compared with trichostatin A. Besides, a study reported a significant decrease in mRNA expression of melatonin receptor MT1 in colorectal cancer compared with the healthy adjacent mucosa tissue [171].

Melatonin has also shown synergistic effect with other anticancer agents on colorectal tumor. Combination of ursolic acid and melatonin led to an enhanced antiproliferative and pro-apoptotic activities in colon cancer cell lines SW480 and LoVo. The enhanced effects were via the cytochrome c/caspase, MMP9/COX-2, and p300/NF- $\mathrm{BB}$ signaling pathways [172].

\section{In vivo studies}

A study investigated the effect of melatonin on a mouse model of colitis-associated colon carcinogenesis (CACC). Melatonin decreased the progression of CACC by downregulating the process of autophagy, and alleviating the level of several inflammatory markers. Melatonin also increased expression of Nrf2 and the associated antioxidant enzymes in the colon of mice with CACC [173]. Constant light environment is related with high incidence of colon cancer, mainly through causing disorders in neuroendocrine colon system [174]. In a study, preneoplastic patterns in colon tissue from animals exposed to constant light environment (14 days; 300 lx) were analyzed, and induction of aberrant crypt foci (ACF) development was observed, characterized by increase of number of $\mathrm{CD}_{133^{+}}$and $\mathrm{CD} 68^{+}$cells. Increase of the proliferative process and decrease of caspase- 3 protein were also observed. However, the above alterations were reversed by melatonin supplementation, through controlling the dysplastic ACF development and the preneoplastic patterns. These results pointed to that melatonin had a great potential to control the preneoplastic patterns induced by constant light [175].

Collectively, melatonin could be a new appealing therapeutic strategy for colorectal cancer, since it could regulate carcinogenesis, development, and progression of colorectal cancer. The underlying mechanisms involve multiple signaling pathways, including regulation of CaMKII, ET-1, Nrf2 signaling pathways, and induction of ACF.

\section{Other cancers}

The anticancer effect of melatonin has also been observed in melanoma. A study revealed that melatonin combined with ER stress (induced by thapsigargin or tunicamycin) decreased cell viability of B16F10 melanoma cells, via the PI3K/Akt/mTOR pathway [176]. In addition, melatonin enhanced the antitumor activity of fisetin in melanoma cells, as shown by enhanced inhibition on cell viability, cell migration and clone formation, as well as the increased apoptosis. The possible mechanism might be through activation of cytochrome c-dependent apoptotic pathway and inhibition of COX-2/iNOS and $\mathrm{NF}-\kappa \mathrm{B} / \mathrm{p} 300$ signaling pathways [177]. In another study, low melatonin concentrations $\left(10^{-9}-10^{-5} \mathrm{M}\right)$ suppressed proliferation of B16 melanoma cells without inhibition on fibroblasts, while the high concentrations (10-4-10$2 \mathrm{M})$ inhibited the cell viability of melanoma cells, but the inhibitory activity was not as marked as that on nontumor cell (3T3 fibroblasts). The ROS production might contribute to melatonin-induced cell viability inhibition at high melatonin concentrations [178]. 
Melatonin also showed anti-cancer effect on pituitary prolactin-secreting tumor. In a study, melatonin induced apoptosis of prolactinoma tumor cells via inducing mitochondrial dysfunction and inhibiting energy metabolism, both in vivo (male rats) and in vitro (prolactinoma cells) [179]. Elevated levels of four mitochondrial respiratory complexes activities and ATP production were observed in E-2-induced prolactinsecretory tumor cells, and melatonin repressed the activities of mitochondrial respiratory complexes and the production of ATP.

Melatonin has also shown anticancer effect on human leiomyosarcoma (LMS) [180]. Melatonin showed significant inhibitory effects on tissue-isolated human LMS xenografts, by suppressing aerobic glycolysis (Warburg effect) and tumor linoleic acid uptake and other related signaling mechanisms. Melatonin at physiological concentration also inhibited cell proliferation and cell invasion in in vitro cell culture studies. Another study showed that melatonin was able to induce cell death on a human alveolar rhabdomyosarcoma cell line in a doseand time-dependent manner [181]. Furthermore, melatonin treatment at 150 and $300 \mu \mathrm{g} / 30 \mathrm{~g}$ bw for 12 consecutive days could induce a very effective oncostatic and cytotoxic activity in mice incubated with Ehrlich ascites tumor cells [182].

Furthermore, melatonin showed anti-apoptotic effects on lymphocytes and neutrophils obtained from rats injected with HL-60 leukemia cells, as shown by significantly inhibiting caspase- 3 and -9 activities, and reverting the proportions of lymphocytes, neutrophils, and eosinophils to their basal values [183]. Besides, melatonin induced cell death in human malignant haematological cell lines, via the activation of the extrinsic pathway of apoptosis, regulated by the improvement in expression of the death receptors Fas, DR4 and DR5 and their ligands Fas L and TRAIL [184]. Moreover, a study investigated melatonin's effect on different cancer cells, including pulmonary adenocarcinoma A549 cell, chondrosarcoma sw-1353 cell, glioblastoma A172 cell, and human acute myeloid leukemia HL-60 cell. A dual effect of melatonin on intracellular redox state was found. That is, oncostatic effect of melatonin depended on its ability to induce either an antioxidant environment (leading to an antiproliferative effect in some tumors) or a prooxidant environment (leading to a cytotoxic effect in some tumors) [185].

Melatonin combined with some chemotherapeutic drugs could exert a synergistic toxic effect on A172 malignant glioma cells and brain tumor stem cells [186], via downregulating the expression and function of adenosine triphosphate-binding cassette transporter ABCG2/BCRP, whose overexpression in malignant glioblastomas is responsible for the multidrug resistance and tumor relapse. Besides, melatonin showed synergistic antitumor effect with vincristine and ifosfamide on SKN-MC human Ewing sarcoma cancer cells, through potentiating extrinsic apoptosis [187].

The anticancer effect of melatonin and possible mechanisms of action are summarized in Table 2, Table 3 and Figure 3, and the synergistic effects of melatonin with other chemotherapy or radiotherapy are summarized in Table 4.

\section{CLINICAL TRIALS}

In clinical trials concerning melatonin's anticancer effect, melatonin was mainly used as an adjuvant therapy with other chemotherapeutic drugs. Several clinical studies suggested that melatonin could enhance the therapeutic efficacy and reduce the toxicities of other anticancer drugs, as shown by increased partial response, induced tumor regression, higher survival rate and relieved symptoms of side effects. According to a clinical trial, treatment of low-dose subcutaneous interleukin-2 (3 million IU/day for 6 days/week for 4 weeks) plus melatonin $(40 \mathrm{mg}$ / day orally) significantly increased 1 year survival rate of patients with metastatic colorectal cancer, compared with supportive care alone $(9 / 25$ vs. $3 / 25, p<0.05)$ [188]. In a phase-II study including 14 patients with metastatic breast cancer, an oral $20 \mathrm{mg} /$ day of melatonin starting 7 days before tamoxifen therapy achieved a partial response in $4 / 14(28.5 \%)$ patients, caused a relief of anxiety in most patients, and did not enhance the toxicity of tamoxifen. Besides, serum levels of IGF-1 were decreased by the combination therapy [189]. Another clinical trial also reported that melatonin could enhance the efficacy of chemotherapy and reduce the toxicity in patients with metastatic solid tumor [190]. Besides, a clinical study evaluated the effect of a concomitant administration of melatonin (20 mg/day orally in the evening) on metastatic NSCL cancer patients receiving a chemotherapeutic regimen consisting of cisplatin and etoposide. Patients receiving concomitant melatonin showed higher overall tumor regression rate and 5-year survival, with a better tolerance to chemotherapy [191]. Similarly, concomitant melatonin with irinotecan achieved a higher percent of disease-control on metastatic colorectal cancer patients than irinotecan alone, because partial response and stable disease were obtained by more patients [192].

Besides, several studies reported that melatonin might be able to improve the sleep and quality of life in patients with breast cancer. In a prospective phase II trial, bedtime melatonin was associated with a significant improvement in objective sleep quality, subjective sleep, sleep fragmentation and quantity, fatigue severity, global quality of life, and social and cognitive functioning scales [193]. Besides, a double-blind, placebo-controlled, randomized clinical trial pointed out that the risk of developing depressive symptoms in subjects who received $6 \mathrm{mg}$ oral melatonin was significantly lower than that of subjects who took placebo [194]. Furthermore, the secondary outcomes of this trial reported that $6 \mathrm{mg}$ 
oral melatonin administration approximately 1 hour before bedtime led to significantly improved sleep efficiency and reduced wake after sleep onset for the 2-week postoperative period [195]. Another randomized, placebo-controlled trial claimed that compared to subjects on placebo, subjects who received melatonin reported significantly increases in subjective sleep quality as measured by the Pittsburgh Sleep Quality Index (PSQI) [196]. Another study showed that melatonin combined with somatostatin, retinoids, vitamin $\mathrm{D}_{3}$ and low dose of cyclophosphamide preformed a positive action in terms of efficacy and survival of breast cancer in human [197]. However, a double-blind, placebo-controlled study reported that short-term melatonin treatment did not produce any significant influence on the estradiol and IGF-1/IGBBP-3 levels in women with a prior history of stages 0-III breast cancer [198]. Furthermore, another double-blind placebo-controlled crossover trial which included 72 patients suggested that $20 \mathrm{mg}$ oral melatonin administration was not able to improve fatigue or other symptoms in patients with advanced cancer [199].

Collectively, in clinical trials, melatonin showed the ability to enhance the therapeutic effect of various anticancer drugs. Meanwhile, melatonin might help improving the sleep and life quality of cancer patients.

\section{CONCLUSIONS AND PROSPECTS}

The effects of melatonin on cancers have been widely studied, with a focus on hormone-dependent cancers. Epidemiological studies concerning the association between body circadian melatonin levels and cancer incidence led to controversial conclusions, which were either significant association or no association at all. Numerous experimental studies have indicated an oncostatic role of melatonin in various cancers, such as breast, ovarian, prostate, oral, gastric, and colorectal cancers. The underlying mechanisms include several molecular pathways, which are associated with antioxidant activity, modulation of melatonin receptors MT1 and MT2, regulation of apoptosis, pro-survival signaling and tumor metabolism, inhibition of angiogenesis, invasion and metastasis, and induction of epigenetic alteration. Melatonin also showed the potential to be utilized as adjuvant of cancer therapies, through reinforcing the therapeutic effects and reducing the side effects of chemotherapies or radiation. In clinical trials, melatonin showed the ability to enhance the therapeutic effect of various anticancer drugs, and might help improving the sleep and life quality of cancer patients. Overall, the impressive efficacy and safety of melatonin support it as a promising agent for the prevention and treatment of cancers.

In the future, several aspects about melatonin's anticancer action should be further investigated. For epidemiological studies, the main problem is the inconsistence of results. This might be because different kinds of sample, sample collection time and assessment methods of melatonin were used. Therefore, different assessment methods of melatonin need to be compared, and the most reliable one should be adopted in future studies. Besides, the effects of different kinds of sample (such as urine, plasma or serum) on the results need to be studied, and the same type of sample should be used. Furthermore, the most appropriate sample collection time should be determined because the melatonin concentration in human body changes with circadian rhythm. For experimental studies, it should be noted that melatonin regulates the physiology and molecular biology of cells through a variety of mechanisms, and cancer is a heterogeneous disease. Therefore, the anticancer efficacy of melatonin was not limited to the aforementioned mechanisms of action. For incidence, autophagy is a prominent feature of programmed cell death, and studies of melatonin's effect on autophagy in cancer cells are very few. Besides, beneficial effects of melatonin against mitochondrial dysfunction in different pathologies have also been described in literature. Thus, there is a possibility that melatonin's oncostatic effect is linked to mitophagy. However, the related researches in this topic are insufficient. Thus, future research might encompass melatonin's effect on autophagy and mitophagy, and other molecular mechanisms involved in its anticancer action. For clinical trials, melatonin's enhancing effect on more anticancer drugs should be further assessed. In addition, its direct effect on patients with manifest cancer should be studied by exogenous melatonin administration to find its oncostatic effects on some cancers and provide information on dosage and long-term safety of melatonin. Moreover, mechanisms of action should be investigated further.

\section{Abbreviations}

The following abbreviations are used in this manuscript:

ACF, aberrant crypt foci; ALT, alanine amino transferase; aMT6s, 6-sulfatoxymelatonin; Apaf-1, apoptotic protease activating factor 1; AR, androgen receptor; AST, aspartate aminotransferase; Bax, Bcl2 associated X protein; Bcl-2, B-cell lymphoma-2; Bcl-xL, B-cell lymphoma-xL; Bim, Bcl-2-interacting mediator; CACC, colitis-associated colon carcinogenesis; cAMP, cyclic adenosine monophosphate; CaMKII, $\mathrm{Ca}^{2+} /$ calmodulin-dependent protein kinase II $\alpha$; CCAR2, cell cycle and apoptosis regulator 2; CHOP, C/EBP homologous protein; COX, cyclooxygenase; DR4, death receptor 4; DR5, death receptor 5; EMT, epithelialmesenchymal transition; EGR, early growth response; EGFR, epidermal growth factor receptor; ER, endoplasmic reticulum; ERK, extracellular regulated protein kinase; ET-1, endothelin-1; Fas, factor associated suicide; Foxp3, 
Forkhead box p3; GPC3, glypican-3; GPCR, G-proteincoupled receptor; GSK $3 \beta$, glycogen synthase kinase $3 \beta$; HCC, hepatocellular carcinoma; HDAC4, histone deacetylase 4; Her-2, human epidermal growth factor receptor2; IAPs, inhibitor of apoptosis proteins; IGF1, insulin-like growth factors; IGFBP-3, insulin-like growth factor-binding protein 3 ; HIF, hypoxia-inducible factor; HSP, heat shock protein; IPO7, importin-7; JNK, c-Jun N-terminal kinase; LAN, light at night; LMS, leiomyosarcoma; MAPK, mitogen-activated protein kinase; MDA, malondialdehyde; MFC, murine foregastric carcinoma; miRNA, microRNA; mTOR, mechanistic target of rapamycin; MMP, matrix metalloproteinase; MyD88, myeloid differentiation factor 88; NF- $\kappa \mathrm{B}$, nuclear factor- $\kappa \mathrm{B}$; NSCLC, non-small cell lung cancer; P53, tumor protein 53; PC-3, prostate cancer cells; PCNA, proliferating cell nuclear antigen; Per2, Period 2; PI3K, phosphatidylinositol 3-kinase; PKA, protein kinase A; PKB, protein kinase $\mathrm{B}$; $\mathrm{PKC}$, protein kinase $\mathrm{C}$; PGE, prostaglandin E; REDD1, regulated in DNA damage and development 1; RCC, renal cell carcinoma; ROCK, Rho-associated protein kinase; ROS, reactive oxygen species; Sirt1, sirtuin 1; SCC, squamous cell lung carcinoma; SENP1, sentrin-specific protease 1; STAT3, signal transducers and activators of transcription 3; TGF, transforming growth factor; TIMP, tissue inhibitor of metalloproteinases; TKIs, tyrosine kinase inhibitors; TLR, toll-like receptors; Tregs, regulatory cells; TRIF, TIRdomain-containing adapter-inducing interferon- $\beta$; TNF, tumor necrosis factor; TRAIL, TNF related apoptosis inducing ligand; TRPV1, transient receptor potential vanilloid 1; VEGF, vascular endothelial growth factor; XIAP, X-linked inhibitor of apoptosis; XPO1, exportin 1.

\section{Author contributions}

Ya Li, Sha Li and Hua-Bin Li conceived this paper; Ya Li, Yue Zhou, Xiao Meng, Jiao-Jiao Zhang and DongPing $\mathrm{Xu}$ wrote this paper; and Sha Li and Hua-Bin $\mathrm{Li}$ revised the paper.

\section{ACKNOWLEDGMENTS}

This work was supported by the National Natural Science Foundation of China (No. 81372976), Key Project of Guangdong Provincial Science and Technology Program (No.2014B020205002), and the Hundred-Talents Scheme of Sun Yat-Sen University.

\section{CONFLICTS OF INTEREST}

The authors declare no conflict of interest.

\section{REFERENCES}

1. Grant SG, Melan MA, Latimer JJ, Witt-Enderby PA. Melatonin and breast cancer: Cellular mechanisms, clinical studies and future perspectives. Expert Rev Mol Med. 2009; 11:e5.

2. Acuña-Castroviejo D, Escames G, Venegas C, Díaz-Casado ME, Lima-Cabello E, López LC, Rosales-Corral S, Tan D, Reiter RJ. Extrapineal melatonin: Sources, regulation, and potential functions. Cell Mol Life Sci. 2014; 71:2997-3025.

3. Ekmekcioglu C. Melatonin receptors in humans: Biological role and clinical relevance. Biomed Pharmacother. 2006; 60:97-108

4. Li AN, Xu XR, Li S, Guo YJ, Liu JL, Li HB. Secretion and bioactivity of melatonin. Int J Mod Biol Med. 2012; 1:2139.

5. Stehle JH, Saade A, Rawashdeh O, Ackermann K, Jilg A, Sebestény T, Maronde E. A survey of molecular details in the human pineal gland in the light of phylogeny, structure, function and chronobiological diseases. J Pineal Res. 2011; 51:17-43.

6. Reiter RJ. Pineal melatonin: Cell biology of its synthesis and of its physiological interactions. Endocr Rev. 1991; 12:151-180.

7. Stehle JH, Von Gall C, Korf HW. Melatonin: A clockoutput, a clock-input. 2003; 15:383-389.

8. Slominski RM, Reiter RJ, Schlabritz-Loutsevitch N, Ostrom RS, Slominski AT. Melatonin membrane receptors in peripheral tissues: Distribution and functions. Mol Cell Endocrinol. 2012; 351:152-166.

9. Stevens RG, Brainard GC, Blask DE, Lockley SW, Motta ME. Breast cancer and circadian disruption from electric lighting in the modern world. CA Cancer J Clin. 2014; 64:207-218.

10. WHO. 2015. Available online: http://www.who.int/ mediacentre/factsheets/fs297/en/ (accessed on 17 September 2016).

11. Siegel RL, Miller KD, Jemal A. Cancer statistics, 2016. CA Cancer J Clin. 2016; 66:7-30.

12. Zhang JJ, Li Y, Zhou T, Xu DP, Zhang P, Li S, Li HB. Bioactivities and health benefits of mushrooms mainly from China. Molecules. 2016; 21:938.

13. Li Y, Zhang JJ, Xu DP, Zhou T, Zhou Y, Li S, Li HB. Bioactivities and health benefits of wild fruits. Int J Mol Sci. 2016; 17:1258.

14. Zhou Y, Zheng J, Li Y, Xu DP, Li S, Chen YM, Li HB. Natural polyphenols for prevention and treatment of cancer. Nutrients. 2016; 8:515.

15. Zheng J, Zhou Y, Li Y, Xu DP, Li S, Li HB. Spices for prevention and treatment of cancers. Nutrients. 2016; 8:495.

16. Xu DP, Zheng J, Zhou Y, Li Y, Li S, Li HB. Extraction of natural antioxidants from the Thelephora ganbajun mushroom by an ultrasound-assisted extraction technique and evaluation of antiproliferative activity of the extract 
against human cancer cells. Int J Mol Sci. 2016; 17:1664.

17. Zhang YJ, Gan RY, Li S, Zhou Y, Li AN, Xu DP, Li HB. Antioxidant phytochemicals for the prevention and treatment of chronic diseases. Molecules. 2015; 20:2113821156.

18. Li AN, Li S, Zhang YJ, Xu XR, Chen YM, Li HB. Resources and biological activities of natural polyphenols. Nutrients. 2014; 6:6020-6047.

19. Li F, Li S, Li HB, Deng GF, Ling WH, Wu S, Xu XR, Chen F. Antiproliferative activity of peels, pulps and seeds of 61 fruits. J Funct Foods. 2013; 5:1298-1309.

20. Li F, Li S, Li HB, Deng GF, Ling WH, Xu XR. Antiproliferative activities of tea and herbal infusions. Food Funct. 2013; 4:530-538.

21. Xia EQ, Deng GF, Guo YJ, Li HB. Biological activities of polyphenols from grapes. Int J Mol Sci. 2010; 11:622-646.

22. Luchetti F, Canonico B, Betti M, Arcangeletti M, Pilolli F, Piroddi M, Canesi L, Papa S, Galli F. Melatonin signaling and cell protection function. Faseb J. 2010; 24:3603-3624.

23. Vijayalaxmi, Thomas CR, Reiter RJ, Herman TS. Melatonin: From basic research to cancer treatment clinics. J Clin Oncol. 2002; 20:2575-2601.

24. Cutando A, Lopez-Valverde A, Arias-Santiago S, De Vicente J, De Diego RG. Role of melatonin in cancer treatment. Anticancer Res. 2012; 32:2747-2753.

25. Srinivasan V, Spence DW, Pandi-Perumal SR, Trakht I, Cardinali DP. Therapeutic actions of melatonin in cancer: Possible mechanisms. Integr Cancer Ther. 2008; 7:189-203.

26. Reppert SM. Melatonin receptors: Molecular biology of a new family of G protein-coupled receptors. J Biol Rhythm. 1997; 12:528-531.

27. Deming SL, Lu W, Beeghly-Fadiel A, Zheng Y, Cai QY, Long JR, Shu XO, Gao YT, Zheng W. Melatonin pathway genes and breast cancer risk among Chinese women. Breast Cancer Res Tr. 2012; 132:693-699.

28. Jung B, Ahmad N. Melatonin in cancer management: Progress and promise. Cancer Res. 2006; 66:9789-9793.

29. Sainz RM, Mayo JC, Rodriguez C, Tan DX, Lopez-Burillo S, Reiter RJ. Melatonin and cell death: Differential actions on apoptosis in normal and cancer cells. Cell Mol Life Sci. 2003; 60:1407-1426.

30. Hill SM, Belancio VP, Dauchy RT, Xiang S, Brimer S, Mao L, Hauch A, Lundberg PW, Summers W, Yuan L, Frasch T, Blask DE. Melatonin: An inhibitor of breast cancer. Endocr Relat Cancer. 2015; 22:R183-R204.

31. Sanchez-Barcelo EJ, Mediavilla MD, Alonso-Gonzalez C, Reiter RJ. Melatonin uses in oncology: Breast cancer prevention and reduction of the side effects of chemotherapy and radiation. Expert Opin Inv Drug. 2012; 21:819-831.

32. Yang WS, Deng Q, Fan WY, Wang WY, Wang X. Light exposure at night, sleep duration, melatonin, and breast cancer: A dose-response analysis of observational studies. Eur J Cancer Prev. 2014; 23:269-276.
33. Abd El Moneim NA, El Masry H, Sorial MM. A molecular case-control study on the association of melatonin hormone and rs\#10830963 single nucleotide polymorphism in its receptor MTNR1B gene with breast cancer. Middle East J cancer. 2015; 6:11-20.

34. Basler M, Jetter A, Fink D, Seifert B, Kullak-Ublick GA, Trojan A. Urinary excretion of melatonin and association with breast cancer: Meta-Analysis and review of the literature. Breast Care. 2014; 9:182-187.

35. Schernhammer ES, Hankinson SE. Urinary melatonin levels and postmenopausal breast cancer risk in the nurses' health study cohort. Cancer Epidem Biomar. 2009; 18:74-79.

36. Travis RC, Allen DS, Fentiman IS, Key TJ. Melatonin and breast cancer: A prospective study. J Natl Cancer Inst. 2004; 96:475-482.

37. Sturgeon SR, Doherty A, Reeves KW, Bigelow C, Stanczyk FZ, Ockene JK, Liu S, Manson JE, Neuhouser ML. Urinary levels of melatonin and risk of postmenopausal breast cancer: Women's health initiative observational cohort. Cancer Epidem Biomar. 2014; 23:629-637.

38. Brown SB, Hankinson SE, Eliassen AH, Reeves KW, Qian J, Arcaro KF, Wegrzyn LR, Willett WC, Schernhammer ES. Urinary melatonin concentration and the risk of breast cancer in nurses' health study II. Am J Epidemiol. 2015; 181:155-162.

39. Wang XS, Tipper S, Appleby PN, Allen NE, Key TJ, Travis RC. First-Morning urinary melatonin and breast cancer risk in the guernsey study. Am J Epidemiol. 2014; 179:584-593.

40. Sigurdardottir LG, Markt SC, Rider JR, Haneuse S, Fall K, Schernhammer ES, Tamimi RM, Flynn-Evans E, Batista JL, Launer L, Harris T, Aspelund T, Stampfer MJ, et al. Urinary melatonin levels, sleep disruption, and risk of prostate cancer in elderly men. Eur Urol. 2015; 67:191-194.

41. Tai S, Huang S, Bao B, Wu M. Urinary melatonin-sulfate/ cortisol ratio and the presence of prostate cancer: A casecontrol study. Sci Rep. 2016; 6:29606.

42. Zhao M, Wan JY, Zeng K, Tong M, Lee AC, Ding JX, Chen Q. The reduction in circulating melatonin level may contribute to the pathogenesis of ovarian cancer: A retrospective study. J Cancer. 2016; 7:831-836.

43. Wang YM, Jin BZ, Ai F, Duan CH, Lu YZ, Dong TF, Fu QL. The efficacy and safety of melatonin in concurrent chemotherapy or radiotherapy for solid tumors: A metaanalysis of randomized controlled trials. Cancer Chemother Pharmacol. 2012; 69:1213-1220.

44. Seely D, Wu P, Fritz H, Kennedy DA, Tsui T, Seely A, Mills E. Melatonin as adjuvant cancer care with and without chemotherapy: A systematic review and meta-analysis of randomized trials. Integr Cancer Ther. 2012; 11:293-303.

45. Poole EM, Schernhammer E, Mills L, Hankinson SE, Tworoger SS. Urinary melatonin and risk of ovarian cancer. Cancer Causes Control. 2015; 26:1501-1506.

46. Parkin DM. International variation. Oncogene. 2004; 23:6329-6340. 
47. Mediavilla MD, Cos S, Sanchez-Barcelo EJ. Melatonin increases p53 and p21 WAF1 expression in MCF-7 human breast cancer cells in vitro. Life Sci. 1999; 65:415-420.

48. Aubert C, Janiaud P, Lecalvez J. Effect of pinealectomy and melatonin on mammary tumor growth in SpragueeDawley rats under different conditions of lighting. J. Neural Transm. 1980; 47:121-130.

49. Tamarkin L, Cohen M, Roselle D, Reichert C, Lippman M, Chabner B. Melatonin inhibition and pinealectomy enhancement of 7,12-dimethylbenz(a)anthracene-induced mammary tumors in the rat. Cancer Res. 1981; 41:44324436.

50. Cos S, Mediavilla MD, Fernandez R, Gonzalez-Lamuno D, Sanchez-Barcelo EJ. Does melatonin induce apoptosis in MCF-7 human breast cancer cells in vitro? J Pineal Res. 2002; 32:90-96.

51. Girgert R, Bartsch C, Hill SM, Kreienberg R, Hanf V. Tracking, the elusive antiestrogenic effect of melatonin: A new methodological approach. Neuroendocrinol Lett. 2003; 24:440-444.

52. Martinez-Campa C, Alonso-Gonzalez C, Mediavilla MD, Cos S, Gonzalez A, Ramos S, Sanchez-Barcelo EJ. Melatonin inhibits both ER alpha activation and breast cancer cell proliferation induced by a metalloestrogen, cadmium. J Pineal Res. 2006; 40:291-296.

53. Cos S, Martinez-Campa C, Mediavilla MD, SanchezBarcelo EJ. Melatonin modulates aromatase activity in MCF-7 human breast cancer cells. J Pineal Res. 2005; 38:136-142.

54. Collins A, Yuan L, Kiefer TL, Cheng Q, Lai L, Hill SM. Overexpression of the MT1 melatonin receptor in MCF7 human breast cancer cells inhibits mammary tumor formation in nude mice. Cancer Lett. 2003; 189:49-57.

55. Lai L, Yuan L, Cheng Q, Dong CM, Mao LL, Hill SM. Alteration of the MT1 melatonin receptor gene and its expression in primary human breast tumors and breast cancer cell lines. Breast Cancer Res Treat. 2009; 118:293305.

56. Jardim-Perassi BV, Lourenco MR, Doho GM, Grigolo IH, Gelaleti GB, Ferreira LC, Borin TF, Moschetta MG, Zuccari D. Melatonin regulates angiogenic factors under hypoxia in breast cancer cell lines. Anticancer Agents Med Chem. 2016; 16:347-358.

57. Goncalves ND, Colombo J, Lopes JR, Gelaleti GB, Moschetta MG, Sonehara NM, Hellmen E, Zanon CD, Oliani SM, Zuccari D. Effect of melatonin in epithelial mesenchymal transition markers and invasive properties of breast cancer stem cells of canine and human cell lines. PloS One. 2016; 11:e0150407.

58. Mao LL, Yuan L, Slakey LM, Jones FE, Burow ME, Hill $\mathrm{SM}$. Inhibition of breast cancer cell invasion by melatonin is mediated through regulation of the p38 mitogen-activated protein kinase signaling pathway. Breast Cancer Res. 2010; 12:R107.
59. Lopes JR, Maschio LB, Jardim-Perassi BV, Moschetta MG, Ferreira LC, Martins GR, Gelaleti GB, Zuccari D. Evaluation of melatonin treatment in primary culture of canine mammary tumors. Oncol Rep. 2015; 33:311-319.

60. Wang JS, Xiao XS, Zhang Y, Shi DB, Chen WB, Fu LY, Liu LQ, Xie FY, Kang TB, Huang WL, Deng WG. Simultaneous modulation of COX-2, p300, Akt, and Apaf1 signaling by melatonin to inhibit proliferation and induce apoptosis in breast cancer cells. J Pineal Res. 2012; 53:7790.

61. Lissoni P, Rovelli F, Malugani F, Bucovec R, Conti A, Maestroni G. Anti-angiogenic activity of melatonin in advanced cancer patients. Neuroendocrinol Lett. 2001; 22:45-47.

62. Alvarez-Garcia V, Gonzalez A, Alonso-Gonzalez C, Martinez-Campa C, Cos S. Regulation of vascular endothelial growth factor by melatonin in human breast cancer cells. J Pineal Res. 2013; 54:373-380.

63. Zuccari D, Jardim BV, Lopes JR, Borin TF, Gelaleti GB, Moschetta MG, Leonel C, Ferreira LC, Maschio LB, Goncalves NN. Evaluation of hypoxia inducible factor 1-Alpha (HIF1) after treatment with melatonin in breast cancer cell line. Eur J Cancer. 2012; 485:S254-S255.

64. Chottanapund S, Van Duursen M, Navasumrit P, Hunsonti P, Timtavorn S, Ruchirawat M, Van den Berg M. Antiaromatase effect of resveratrol and melatonin on hormonal positive breast cancer cells co-cultured with breast adipose fibroblasts. Toxicol in Vitro. 2014; 28:1215-1221.

65. Martinez-Campa C, Gonzalez A, Mediavilla MD, AlonsoGonzalez C, Alvarez-Garcia V, Sanchez-Barcelo EJ, Cos S. Melatonin inhibits aromatase promoter expression by regulating cyclooxygenases expression and activity in breast cancer cells. Br J Cancer. 2009; 101:1613-1619.

66. Knower KC, To SQ, Takagi K, Miki Y, Sasano H, Simpson ER, Clyne CD. Melatonin suppresses aromatase expression and activity in breast cancer associated fibroblasts. Breast Cancer Res Treat. 2012; 132:765-771.

67. Alvarez-Garcia V, Gonzalez A, Alonso-Gonzalez C, Martinez-Campa C, Cos S. Melatonin interferes in the desmoplastic reaction in breast cancer by regulating cytokine production. J Pineal Res. 2012; 52:282-290.

68. Lee SE, Kim SJ, Yang H, Jeong SI, Hwang SY, Park CS, Park YS. Molecular analysis of melatonin-induced changes in breast cancer cells: Microarray study of anti-cancer effect of melatonin. Biochip J. 2011; 5:353-361.

69. Lee SE, Kim SJ, Youn JP, Hwang SY, Park CS, Park YS. MicroRNA and gene expression analysis of melatoninexposed human breast cancer cell lines indicating involvement of the anticancer effect. J Pineal Res. 2011; 51:345-352.

70. Lee SE, Kim SJ, Yoon HJ, Yu SY, Yang H, Il Jeong S, Hwang SY, Park CS, Park YS. Genome-wide profiling in melatonin-exposed human breast cancer cell lines identifies differentially methylated genes involved in the anticancer 
effect of melatonin. J Pineal Res. 2013; 54:80-88.

71. Mori F, Ferraiuolo M, Santoro R, Sacconi A, Goeman F, Pallocca M, Pulito C, Korita E, Fanciulli M, Muti P, Blandino G, Strano S. Multitargeting activity of miR-24 inhibits long-term melatonin anticancer effects. Oncotarget. 2016; 7:20532-20548. doi: 10.18632/oncotarget. 7978.

72. Yuan L, Collins AR, Dai J, Dubocovich ML, Hill SM. MT1 melatonin receptor overexpression enhances the growth suppressive effect of melatonin in human breast cancer cells. Mol Cell Endocrinol. 2002; 192:147-156.

73. Mao LL, Yuan L, Xiang SL, Zeringue SB, Dauchy RT, Blask DE, Hauch A, Hill SM. Molecular deficiency (ies) in MT1 melatonin signaling pathway underlies the melatoninunresponsive phenotype in MDA- MB-231 human breast cancer cells. J Pineal Res. 2014; 56:246-253.

74. Kosar PA, Naziroglu M, Ovey IS, Cig B. Synergic effects of doxorubicin and melatonin on apoptosis and mitochondrial oxidative stress in MCF-7 breast cancer cells: Involvement of TRPV1 channels. J Membrane Biol. 2016; 249:129-140.

75. Yun SM, Woo SH, Oh ST, Hong SE, Choe TB, Ye SK, Kim EK, Seong MK, Kim HA, Noh WC, Lee JK, Jin HO, Lee $\mathrm{YH}$, et al. Melatonin enhances arsenic trioxide-induced cell death via sustained upregulation of Redd1 expression in breast cancer cells. Mol Cell Endocrinol. 2016; 422:64-73.

76. Jung JH, Sohn EJ, Shin EA, Lee D, Kim B, Jung DB, Kim JH, Yun M, Lee HJ, Park YK, Kim SH. Melatonin suppresses the expression of $45 \mathrm{~S}$ preribosomal RNA and upstream binding factor and enhances the antitumor activity of puromycin in MDA-MB-231 breast cancer cells. Evid Based Complement Alternat Med. 2013; 2013:879746.

77. Margheri M, Pacini N, Tani A, Nosi D, Squecco R, Dama A, Masala E, Francini F, Zecchi-Orlandini S, Formigli L. Combined effects of melatonin and all-trans retinoic acid and somatostatin on breast cancer cell proliferation and death: Molecular basis for the anticancer effect of these molecules. Eur J Pharmacol. 2012; 681:34-43.

78. Proietti S, Cucina A, D'Anselmi F, Dinicola S, Pasqualato A, Lisi E, Bizzarri M. Melatonin and vitamin D-3 synergistically down-regulate Akt and MDM2 leading to TGF -1-dependent growth inhibition of breast cancer cells. J Pineal Res. 2011; 50:150-158.

79. Alonso-Gonzalez C, Gonzalez A, Martinez-Campa C, Gomez-Arozamena J, Cos S. Melatonin sensitizes human breast cancer cells to ionizing radiation by downregulating proteins involved in double-strand DNA break repair. J Pineal Res. 2015; 58:189-197.

80. Alonso-Gonzalez C, Gonzalez A, Martinez-Campa C, Menendez-Menendez J, Gomez-Arozamena J, Garcia-Vidal A, Cos S. Melatonin enhancement of the radiosensitivity of human breast cancer cells is associated with the modulation of proteins involved in estrogen biosynthesis. Cancer Lett. 2016; 370:145-152.

81. Borin TF, Arbab AS, Gelaleti GB, Ferreira LC, Moschetta MG, Jardim-Perassi BV, Iskander A, Varma N, Shankar
A, Coimbra VB, Fabri VA, de Oliveira JG, Zuccari D. Melatonin decreases breast cancer metastasis by modulating Rho-associated kinase protein-1 expression. J Pineal Res. 2016; 60:3-15.

82. Jardim-Perassi BV, Arbab AS, Ferreira LC, Borin TF, Varma N, Iskander A, Shankar A, Ali MM, Zuccari D. Effect of melatonin on tumor growth and angiogenesis in xenograft model of breast cancer. PloS One. 2014; 9:e853111.

83. Schwimmer H, Metzer A, Pilosof Y, Szyf M, Machnes ZM, Fares F, Harel O, Haim A. Light at night and melatonin have opposite effects on breast cancer tumors in mice assessed by growth rates and global DNA methylation. Chronobiol Int. 2014; 31:144-150.

84. Mao LL, Dauchy RT, Blask DE, Slakey LM, Xiang SL, Yuan L, Dauchy EM, Shan B, Brainard GC, Hanifin JP, Frasch T, Duplessis TT, Hill SM. Circadian gating of Epithelial-to-Mesenchymal transition in breast cancer cells via Melatonin-Regulation of GSK3. Mol Endocrinol. 2012; 26:1808-1820.

85. Kassayova M, Bobrov N, Strojny L, Orendas P, Demeckova V, Jendzelovsky R, Kubatka P, Kiskova T, Kruzliak P, Adamkov M, Bomba A, Fedorocko P. Anticancer and immunomodulatory effects of lactobacillus plantarum LS/07, inulin and melatonin in NMU-induced rat model of breast cancer. Anticancer Res. 2016; 36:2719-2728.

86. Talib WH, Saleh S. Propionibacterium acnes augments antitumor, anti-angiogenesis and immunomodulatory effects of melatonin on breast cancer implanted in mice. PloS One. 2015; 10:e1243844.

87. Ma C, Li LX, Zhang Y, Xiang C, Ma T, Ma ZQ, Zhang ZP. Protective and sensitive effects of melatonin combined with adriamycin on ER plus (estrogen receptor) breast cancer. Eur J Gynaecol Oncol. 2015; 36:197-202.

88. Orendas P, Kubatka P, Bojkova B, Kassayova M, Kajo K, Vybohova D, Kruzliak P, Pec M, Adamkov M, Kapinova A, Adamicova K, Sadlonova V, Chmelova M, et al. Melatonin potentiates the anti-tumour effect of pravastatin in rat mammary gland carcinoma model. Int J Exp Pathol. 2014; 95:401-410.

89. Xiang SL, Dauchy RT, Hauch A, Mao LL, Yuan L, Wren MA, Belancio VP, Mondal D, Frasch T, Blask DE, Hill SM. Doxorubicin resistance in breast cancer is driven by light at night-induced disruption of the circadian melatonin signal. J Pineal Res. 2015; 59:60-69.

90. Dauchy RT, Xiang SL, Mao LL, Brimer S, Wren MA, Yuan L, Anbalagan M, Hauch A, Frasch T, Rowan BG, Blask DE, Hill SM. Circadian and melatonin disruption by exposure to light at night drives intrinsic resistance to tamoxifen therapy in breast cancer. Cancer Res. 2014; 74:4099-4110.

91. Wong MCS, Goggins WB, Wang HHX, Fung FDH, Leung C, Wong SYS, Ng CF, Sung JJY. Global incidence and mortality for prostate cancer: Analysis of temporal patterns and trends in 36 countries. Eur Urol. 2016; 70:862-874. 
92. Sainz RM, Mayo JC, Tan DX, Leon J, Manchester L, Reiter RJ. Melatonin reduces prostate cancer cell growth leading to neuroendocrine differentiation via a receptor and PKA independent mechanism. Prostate. 2005; 63:29-43.

93. Sohn EJ, Won G, Lee J, Lee S, Kim SH. Upregulation of miRNA3195 and miRNA374b mediates the AntiAngiogenic properties of melatonin in hypoxic PC-3 prostate cancer cells. J Cancer. 2015; 6:19-28.

94. Tam CW, Shiu S. Functional interplay between melatonin receptor-mediated antiproliferative signaling and androgen receptor signaling in human prostate epithelial cells: Potential implications for therapeutic strategies against prostate cancer. J Pineal Res. 2011; 51:297-312.

95. Shiu S, Leung WY, Tam CW, Liu V, Yao KM. Melatonin MT1 receptor-induced transcriptional up-regulation of p27(Kip1) in prostate cancer antiproliferation is mediated via inhibition of constitutively active nuclear factor kappa B (NF-B): Potential implications on prostate cancer chemoprevention and therapy. J Pineal Res. 2013; 54:69-79.

96. Cho SY, Lee HJ, Jeong SJ, Lee HJ, Kim HS, Chen CY, Lee EO, Kim SH. Sphingosine kinase 1 pathway is involved in melatonin-induced HIF-1 alpha inactivation in hypoxic PC-3 prostate cancer cells. J Pineal Res. 2011; 51:87-93.

97. Jung-Hynes B, Nihal M, Zhong W, Ahmad N. Role of sirtuin histone deacetylase SIRT1 in prostate cancer: A target for prostate cancer management via its inhibition? J Biol Chem. 2009; 284:3823-3832.

98. Jung-Hynes B, Schmit TL, Reagan-Shaw SR, Siddiqui IA, Mukhtar H, Ahmad N. Melatonin, a novel Sirt1 inhibitor, imparts antiproliferative effects against prostate cancer in vitro in culture and in vivo in TRAMP model. J Pineal Res. 2011; 50:140-149.

99. Rodriguez-Garcia A, Mayo JC, Hevia D, Quiros-Gonzalez I, Navarro M, Sainz RM. Phenotypic changes caused by melatonin increased sensitivity of prostate cancer cells to cytokine-induced apoptosis. J Pineal Res. 2013; 54:33-45.

100. Jung-Hynes B, Huang W, Reiter RJ, Ahmad N. Melatonin resynchronizes dysregulated circadian rhythm circuitry in human prostate cancer cells. J Pineal Res. 2010; 49:60-68.

101. Dauchy RT, Hoffman AE, Wren-Dail MA, Hanifin JP, Warfield B, Brainard GC, Xiang S, Yuan L, Hill SM, Belancio VP, Dauchy EM, Smith K, Blask DE. Daytime blue light enhances the nighttime circadian melatonin inhibition of human prostate cancer growth. Comparative Med. 2015; 65:473-485.

102. Paroni R, Terraneo L, Bonomini F, Finati E, Virgili E, Bianciardi P, Favero G, Fraschini F, Reiter RJ, Rezzani R, Samaja M. Antitumour activity of melatonin in a mouse model of human prostate cancer: Relationship with hypoxia signalling. J Pineal Res. 2014; 57:43-52.

103. Dauchy RT, Cecil KS, Dauchy EM, Hanifin JP, Mao LL, Slakey LM, Belancio VP, Hill SM, Brainard GC, Blask DE. Melatonin-depleted blood from healthy adult men exposed to environmental light at night stimulates growth, signal transduction and metabolic activity of tissue-isolated human prostate cancer xenografts in nude rats. Cancer Res. 2011; $71: 1324$

104. Jablonska K, Pula B, Zemla A, Kobierzycki C, Kedzia W, Nowak-Markwitz E, Spaczynski M, Zabel M, PodhorskaOkolow M, Dziegiel P. Expression of the MT1 melatonin receptor in ovarian cancer cells. Int J Mol Sci. 2014; 15:23074-23089.

105. Koshiyama M, Matsumura N, Konishi I. Recent concepts of ovarian carcinogenesis: Type i and type II. Biomed Res Int. 2014; 2014:1-11.

106. Shen CJ, Chang CC, Chen YT, Lai CS, Hsu YC. Melatonin suppresses the growth of ovarian cancer cell lines (OVCAR-429 and PA-1) and potentiates the effect of g1 arrest by targeting CDKs. Int J Mol Sci. 2016; 17:176.

107. Kim JH, Jeong SJ, Kim B, Yun SM, Choi DY, Kim SH. Melatonin synergistically enhances cisplatin-induced apoptosis via the dephosphorylation of ERK/p90 ribosomal S6 kinase/heat shock protein 27 in SK-OV-3 cells. J Pineal Res. 2012; 52:244-252.

108. Chuffa L, Fioruci-Fontanelli BA, Mendes LO, Favaro WJ, Pinheiro P, Martinez M, Martinez FE. Characterization of chemically induced ovarian carcinomas in an EthanolPreferring rat model: Influence of Long-Term melatonin treatment. PloS One. 2013; 8:e8167612.

109. Chuffa L, Alves MS, Martinez M, Camargo I, Pinheiro P, Domeniconi RF, Junior L, Martinez FE. Apoptosis is triggered by melatonin in an in vivo model of ovarian carcinoma. Endocr Relat Cancer. 2016; 23:65-76.

110. Chuffa L, Fioruci-Fontanelli BA, Mendes LO, Seiva F, Martinez M, Favaro WJ, Domeniconi RF, Pinheiro P, Dos Santos LD, Martinez FE. Melatonin attenuates the TLR4mediated inflammatory response through MyD88-and TRIF-dependent signaling pathways in an in vivo model of ovarian cancer. BMC Cancer. 2015; 15:34.

111. Sheng Q, Liu J. The therapeutic potential of targeting the EGFR family in epithelial ovarian cancer. Brit J Cancer. 2011; 104:1241-1245.

112. Ferreira GM, Martinez M, Camargo I, Domeniconi RF, Martinez FE, Chuffa L. Melatonin attenuates her-2, p38 MAPK, p-AKT, and mTOR levels in ovarian carcinoma of Ethanol-Preferring rats. J Cancer. 2014; 5:728-735.

113. Scarinci IC, Garcia FAR, Kobetz E, Partridge EE, Brandt HM, Bell MC, Dignan M, Ma GX, Daye JL, Castle PE. Cervical cancer prevention. Cancer. 2010; 116: 2531-2542.

114. Pariente R, Pariente JA, Rodriguez AB, Espino J. Melatonin sensitizes human cervical cancer HeLa cells to cisplatininduced cytotoxicity and apoptosis: Effects on oxidative stress and DNA fragmentation. J Pineal Res. 2016; 60:5564.

115. Dauchy RT, Dauchy EM, Mao LL, Wren MA, Belancio VP, Hill SM, Blask DE. The circadian neurohormone melatonin inhibits aerobic glycolysis (Warburg effect) and fatty acid metabolic signaling in human colorectal and cervical 
cancer. Cancer Res. 2013; 73:4001.

116. Dauchy RT, Dauchy EM, Belancio VP, Mao LL, Hill SM, Sauer LA, Blask DE. Melatonin inhibition of linoleic acid transport and 13-HODE production in HeLa human cervical adenocarcinoma occurs via receptor-mediated signal transduction. Cancer Res. 2012; 72:5167.

117. McAlpine JN, Temkin SM, Mackay HJ. Endometrial cancer: Not your grandmother's cancer. Cancer. 2016; 122:2787-2798.

118. Kanishi Y, Kobayashi Y, Noda S, Ishizuka B, Saito K. Differential growth inhibitory effect of melatonin on two endometrial cancer cell lines. J Pineal Res. 2000; 28:227233.

119. Ciortea R, Costin N, Braicu I, Haragas D, Hudacsko A, Bondor C, Mihu D, Mihu CM. Effect of melatonin on intraabdominal fat in correlation with endometrial proliferation in ovariectomized rats. Anticancer Res. 2011; 31:26372643.

120. Warnakulasuriya S. Global epidemiology of oral and oropharyngeal cancer. Oral Oncol. 2009; 45:309-316.

121. Yeh CM, Lin CW, Yang JS, Yang WE, Su SC, Yang SF. Melatonin inhibits TPA-induced oral cancer cell migration by suppressing matrix metalloproteinase-9 activation through the histone acetylation. Oncotarget. 2016; 7:2195221967. doi: 10.18632/oncotarget.8009.

122. Goncalves ND, Rodrigues RV, Jardim-Perassi BV, Moschetta MG, Lopes JR, Colombo J, Zuccari D. Molecular markers of angiogenesis and metastasis in lines of oral carcinoma after treatment with melatonin. Anticancer Agents Med Chem. 2014; 14:1302-1311.

123. D'Alessandro LA, Meyer R, Klingmüller U. Hepatocellular carcinoma: A systems biology perspective. Front Physiol. 2013; 4:28.

124. Zhou Y, Li Y, Zhou T, Zheng J, Li S, Li H. Dietary natural products for prevention and treatment of liver cancer. Nutrients. 2016; 8:156.

125. Kapitanov T, Neumann UP, Schmeding M. Hepatocellular carcinoma in liver cirrhosis: Surgical resection versus transarterial chemoembolization-a Meta-Analysis. Gastroent Res Pract. 2015; 2015:1-8.

126. Ordonez R, Carbajo-Pescador S, Prieto-Dominguez N, Garcia-Palomo A, Gonzalez-Gallego J, Mauriz JL. Inhibition of matrix metalloproteinase- 9 and nuclear factor kappa B contribute to melatonin prevention of motility and invasiveness in HepG2 liver cancer cells. J Pineal Res. 2014; 56:20-30.

127. Carbajo-Pescador S, Ordonez R, Benet M, Jover R, GarciaPalomo A, Mauriz JL, Gonzalez-Gallego J. Inhibition of VEGF expression through blockade of Hifl alpha and STAT3 signaling mediates the anti-angiogenic effect of melatonin in HepG2 liver cancer cells. Brit J Cancer. 2013; 109:83-91

128. Fan LL, Sun GP, Ma T, Zhong F, Wei W. Melatonin overcomes apoptosis resistance in human hepatocellular carcinoma by targeting Survivin and XIAP. J Pineal Res. 2013; 55:174-183.

129. Carbajo-Pescador S, Steinmetz C, Kashyap A, Lorenz S, Mauriz JL, Heise M, Galle PR, Gonzalez-Gallego J, Strand $\mathrm{S}$. Melatonin induces transcriptional regulation of Bim by FoxO3a in HepG2 cells. Brit J Cancer. 2013; 108:442-449.

130. Carbajo-Pescador S, Garcia-Palomo A, Martin-Renedo J, Piva M, Gonzalez-Gallego J, Mauriz JL. Melatonin modulation of intracellular signaling pathways in hepatocarcinoma HepG2 cell line: Role of the MT1 receptor. J Pineal Res. 2011; 51:463-471.

131. Zha LX, Fan LL, Sun GP, Wang H, Ma T, Zhong F, Wei W. Melatonin sensitizes human hepatoma cells to endoplasmic reticulum stress-induced apoptosis. J Pineal Res. 2012; 52:322-331.

132. Verma D, Hashim OH, Jayapalan JJ, Subramanian P. Effect of melatonin on antioxidant status and circadian activity rhythm during hepatocarcinogenesis in mice. J Cancer Res Ther. 2014; 10:1040-1044.

133. Moreira AJ, Ordonez R, Cerski CT, Picada JN, GarciaPalomo A, Marroni NP, Mauriz JL, Gonzalez-Gallego J. Melatonin activates endoplasmic reticulum stress and apoptosis in rats with diethylnitrosamine-induced hepatocarcinogenesis. PloS One. 2015; 10:e014451712.

134. Compérat E, Camparo P. Histological classification of malignant renal tumours at a time of major diagnostic and therapeutic changes. Diagn Interv Imaging. 2012; 93:221231.

135. Lin Y, Lee L, Lee W, Chu C, Tan P, Yang Y, Chen W, Yang S, Hsiao M, Chien M. Melatonin inhibits MMP9 transactivation and renal cell carcinoma metastasis by suppressing Akt-MAPKs pathway and NF-B DNA-binding activity. J Pineal Res. 2016; 60:277-290.

136. Park EJ, Woo SM, Min KJ, Kwon TK. Transcriptional and post-translational regulation of Bim controls apoptosis in melatonin-treated human renal cancer Caki cells. J Pineal Res. 2014; 56:97-106.

137. Min KJ, Kim HS, Park EJ, Kwon TK. Melatonin enhances thapsigargin-induced apoptosis through reactive oxygen species-mediated upregulation of CCAAT-enhancerbinding protein homologous protein in human renal cancer cells. J Pineal Res. 2012; 53:99-106.

138. Um HJ, Park JW, Kwon TK. Melatonin sensitizes Caki renal cancer cells to kahweol-induced apoptosis through CHOP-mediated up-regulation of PUMA. J Pineal Res. 2011; 50:359-366.

139. Costa G, Thuler LCS, Ferreira CG. Epidemiological changes in the histological subtypes of 35,018 non-smallcell lung cancer cases in Brazil. Lung Cancer. 2016; 97:6672.

140. Lu JJ, Fu LY, Tang ZP, Zhang CL, Qin LJ, Wang JS, Yu ZL, Shi DB, Xiao XS, Xie FY, Huang WL, Deng WG. Melatonin inhibits AP-2 /hTERT, NF-B/COX-2 and $\mathrm{Akt} / \mathrm{ERK}$ and activates caspase/Cyto $\mathrm{C}$ signaling to 
enhance the antitumor activity of berberine in lung cancer cells. Oncotarget. 2016; 7:2985-3001. doi: 10.18632/ oncotarget.6407.

141. Ma ZQ, Yang Y, Fan CX, Han J, Wang DJ, Di SY, Hu W, Liu D, Li XF, Reiter RJ, Yan XL. Melatonin as a potential anticarcinogen for non-small-cell lung cancer. Oncotarget. 2016; 7:46768-46784. doi: 10.18632/oncotarget.8776.

142. Kim W, Jeong JW, Kim JE. CCAR2 deficiency augments genotoxic stress-induced apoptosis in the presence of melatonin in non-small cell lung cancer cells. Tumor Biol. 2014; 35:10919-10929.

143. Zhou QY, Gui SY, Zhou Q, Wang Y. Melatonin inhibits the migration of human lung adenocarcinoma a549 cell lines involving JNK/MAPK pathway. PloS One. 2014; 9:e1011327.

144. Yun M, Kim EO, Lee D, Kim JH, Kim J, Lee H, Lee J, Kim SH. Melatonin sensitizes h1975 Non-Small-Cell lung cancer cells harboring a T790M-Targeted epidermal growth factor receptor mutation to the tyrosine kinase inhibitor gefitinib. Cell Physiol Biochem. 2014; 34:865-872.

145. Crew KD, Neugut AI. Epidemiology of gastric cancer. World J Gastroentero. 2006; 12:354-362.

146. Torre LA, Bray F, Siegel RL, Ferlay J, Lortet-Tieulent J, Jemal A. Global cancer statistics, 2012. CA Cancer J Clin. 2015; 65:87-108.

147. Wang RX, Liu H, Xu L, Zhang H, Zhou RX. Involvement of nuclear receptor RZR/ROR gamma in melatonin-induced HIF-1 alpha inactivation in SGC-7901 human gastric cancer cells. Oncol Rep. 2015; 34:2541-2546.

148. Zhou RX, Wang RX, Song J, Zhang H, Luo JH, Liu H. Melatonin inhibit the angiogenesis of gastric cancer by nuclear receptor. Faseb J. 2015; 291.

149. Li WM, Fan MD, Chen YN, Zhao Q, Song CY, Yan Y, Jin Y, Huang ZM, Lin CJ, Wu JS. Melatonin induces cell apoptosis in AGS cells through the activation of JNK and p38 MAPK and the suppression of nuclear Factor-Kappa b: A novel therapeutic implication for gastric cancer. Cell Physiol Biochem. 2015; 37:2323-2338.

150. Zhang S, Qi Y, Zhang H, He W, Zhou Q, Gui S, Wang Y. Melatonin inhibits cell growth and migration, but promotes apoptosis in gastric cancer cell line, SGC7901. Biotech Histochem. 2013; 88:281-289.

151. Xu L, Liu H, Zhang H, Wang RX, Song J, Zhou RX. Growth-Inhibitory activity of melatonin on murine foregastric carcinoma cells in vitro and the underlying molecular mechanism. Anat Rec. 2013; 296:914-920.

152. Liu H, Xu L, Wei JE, Xie MR, Wang SE, Zhou RX. Role of $\mathrm{CD} 4+\mathrm{CD} 25+$ regulatory $t$ cells in Melatonin-Mediated inhibition of murine gastric cancer cell growth in vivo and in vitro. Anat Rec (Hoboken). 2011; 294:781-788.

153. Zhang SM, Zuo L, Gui SY, Zhou Q, Wei W, Wang Y. Induction of cell differentiation and promotion of endocan gene expression in stomach cancer by melatonin. Mol Biol Rep. 2012; 39:2843-2849.
154. Wu SM, Lin WY, Shen CC, Pan HC, Keh-Bin W, Chen YC, Jan YJ, Lai DW, Tang SC, Tien HR, Chiu CS, Tsai TC, Lai YL, et al. Melatonin set out to ER stress signaling thwarts epithelial mesenchymal transition and peritoneal dissemination via calpain-mediated $\mathrm{C} / \mathrm{EBP}$ and NFB cleavage. J Pineal Res. 2016; 60:142-154.

155. Leja-Szpak A, Jaworek J, Pierzchalski P, Reiter RJ. Melatonin induces pro-apoptotic signaling pathway in human pancreatic carcinoma cells (PANC-1). J Pineal Res. 2010; 49:248-255.

156. Han SS, Jang JY, Kim SW, Kim WH, Lee KU, Park YH. Analysis of long-term survivors after surgical resection for pancreatic cancer. Pancreas. 2006; 32:271-275.

157. Talar-Wojnarowska R, Malecka-Panas E. Molecular pathogenesis of pancreatic adenocarcinoma: Potential clinical implications. Med Sci Monitor. 2006; 12:RA186RA193.

158. Lv D, Cui PL, Yao SW, Xu YQ, Yang ZX. Melatonin inhibits the expression of vascular endothelial growth factor in pancreatic cancer cells. Chinese J Cancer Res. 2012; 24:310-316.

159. Gonzalez A, Del Castillo-Vaquero A, Miro-Moran A, Tapia JA, Salido GM. Melatonin reduces pancreatic tumor cell viability by altering mitochondrial physiology. J Pineal Res. 2011; 50:250-260.

160. Xu CF, Wu AR, Zhu H, Fang HY, Xu LL, Ye JX, Shen JQ. Melatonin is involved in the apoptosis and necrosis of pancreatic cancer cell line SW-1990 via modulating of Bcl2/Bax balance. Biomed Pharmacother. 2013; 67:133-139.

161. Uguz AC, Cig B, Espino J, Bejarano I, Naziroglu M, Rodriguez AB, Pariente JA. Melatonin potentiates chemotherapy-induced cytotoxicity and apoptosis in rat pancreatic tumor cells. J Pineal Res. 2012; 53:91-98.

162. Ruiz-Rabelo J, Vazquez R, Arjona A, Perea D, Montilla P, Tunez I, Muntane J, Padillo J. Improvement of capecitabine antitumoral activity by melatonin in pancreatic cancer. Pancreas. 2011; 40:410-414.

163. Lea A, Allingham-Hawkins D, Levine S. BRAF p.Val600Glu (V600E) testing for assessment of treatment options in metastatic colorectal cancer. PLoS Curr. 2010; 2:RRN1187.

164. Buldak RJ, Pilc-Gumula K, Buldak L, Witkowska D, Kukla M, Polaniak R, Zwirska-Korczala K. Effects of ghrelin, leptin and melatonin on the levels of reactive oxygen species, antioxidant enzyme activity and viability of the HCT 116 human colorectal carcinoma cell line. Mol Med Rep. 2015; 12:2275-2282.

165. Garcia-Navarro A, Gonzalez-Puga C, Escames G, Lopez LC, Lopez A, Lopez-Cantarero M, Camacho E, Espinosa A, Gallo MA, Acuna-Castroviejo D. Cellular mechanisms involved in the melatonin inhibition of HT-29 human colon cancer cell proliferation in culture. J Pineal Res. 2007; 43:195-205.

166. Wei JY, Li WM, Zhou LL, Lu QN, He W. Melatonin 
induces apoptosis of colorectal cancer cells through HDAC4 nuclear import mediated by CaMKII inactivation. J Pineal Res. 2015; 58:429-438.

167. Rosanò L, Spinella F, Bagnato A. Endothelin 1 in cancer: Biological implications and therapeutic opportunities. Nat Rev Cancer. 2013; 13:637-651.

168. Leon J, Casado J, Ruiz S, Zurita MS, Gonzalez-Puga C, Rejon JD, Gila A, de Rueda PM, Pavon EJ, Reiter RJ, RuizExtremera A, Salmeron J. Melatonin reduces endothelin-1 expression and secretion in colon cancer cells through the inactivation of FoxO-1 and NF- B. J Pineal Res. 2014; 56:415-426

169. Batista A, Da Silva TG, Teixeira A, de Medeiros PL, Teixeira VW, Alves LC, Dos Santos F, Silva EC. Ultrastructural aspects of melatonin cytotoxicity on Caco-2 cells in vitro. Micron. 2014; 59:17-23.

170. Hong Y, Won J, Lee Y, Lee S, Park K, Chang KT, Hong $\mathrm{Y}$. Melatonin treatment induces interplay of apoptosis, autophagy, and senescence in human colorectal cancer cells. J Pineal Res. 2014; 56:264-274.

171. Nemeth C, Humpeler S, Kallay E, Mesteri I, Svoboda M, Rogelsperger O, Klammer N, Thalhammer T, Ekmekcioglu C. Decreased expression of the melatonin receptor 1 in human colorectal adenocarcinomas. J Biol Regul Homeost Agents. 2011; 25:531-542.

172. Wang JS, Guo W, Chen WB, Yu WD, Tian Y, Fu LY, Shi DB, Tong B, Xiao XS, Huang WL, Deng WG. Melatonin potentiates the antiproliferative and pro-apoptotic effects of ursolic acid in colon cancer cells by modulating multiple signaling pathways. J Pineal Res. 2013; 54:406-416.

173. Trivedi PP, Jena GB, Tikoo KB, Kumar V. Melatonin modulated autophagy and Nrf2 signaling pathways in mice with colitis-associated colon carcinogenesis. Mol Carcinogen. 2016; 55:255-267.

174. Anisimov VN, Kvetnoy IM, Chumakova NK, Kvetnaya TV, Molotkov AO, Pogudina NA, Popovich IG, Popuchiev VV, Zabezhinski MA, Bartsch H, Bartsch C. Melatonin and colon carcinogenesis. II. Intestinal melatonincontaining cells and serum melatonin level in rats with 1,2-dimethylhydrazine-induced colon tumors. Exp Toxicol Pathol. 1999; 51:47-52.

175. Kannen V, Marini T, Zanette DL, Frajacomo FT, Silva G, Silva WA, Garcia SB. The melatonin action on stromal stem cells within pericryptal area in colon cancer model under constant light. Biochem Bioph Res Co. 2011; 405:593-598.

176. Kim HS, Kim TJ, Yoo YM. Melatonin combined with endoplasmic reticulum stress induces cell death via the $\mathrm{PI} 3 \mathrm{~K} / \mathrm{Akt} / \mathrm{mTOR}$ pathway in B16F10 melanoma cells. PloS One. 2014; 9:e926273.

177. Yi CH, Zhang Y, Yu ZL, Xiao Y, Wang JS, Qiu HJ, Yu WD, Tang RR, Yuan YH, Guo W, Deng WG. Melatonin enhances the anti-tumor effect of fisetin by inhibiting COX2/iNOS and NF-B/p300 signaling pathways. PloS One. 2014; 9:e999437.
178. Bonmati-Carrion MA, Alvarez-Sanchez N, Hardeland R, Madrid JA, Rol MA. A comparison of b16 melanoma cells and 3T3 fibroblasts concerning cell viability and ROS production in the presence of melatonin, tested over a wide range of concentrations. Int J Mol Sci. 2013; 14:3901-3920.

179. Wang BQ, Yang QH, Xu RK, Xu JN. Elevated levels of mitochonrial respiratory complexes activities and ATP production in 17--estradiol-induced prolactin-secretory tumor cells in male rats are inhibited by melatonin in vivo and in vitro. Chin Med J (Engl). 2013; 126:4724-4730.

180. Mao LL, Dauchy RT, Blask DE, Dauchy EM, Slakey LM, Brimer S, Yuan L, Xiang SL, Hauch A, Smith K, Frasch T, Belancio VP, Wren MA, et al. Melatonin suppression of aerobic glycolysis (Warburg effect), survival signalling and metastasis in human leiomyosarcoma. J Pineal Res. 2016; 60:167-177.

181. Burattini S, Battistelli M, Codenotti S, Falcieri E, Fanzani A, Salucci S. Melatonin action in tumor skeletal muscle cells: An ultrastructural study. Acta Histochem. 2016; 118:278-285.

182. Batista APC, Da Silva TG, Teixeira AAC, de Medeiros PL, Teixeira VW, Alves LC, Dos Santos FAB. Melatonin effect on the ultrastructure of Ehrlich ascites tumor cells, lifetime and histopathology in Swiss mice. Life Sci. 2013; 93:882888.

183. Delgado J, Terron M, Garcia-Martinez V, Lopez-Sanchez C, Barriga C, Pariente JA, Rodriguez AB. Oral melatonin administration and programmed cell death of neutrophils, lymphocytes, and other cell types from rats injected with HL-60 cells. J Appl Biomed. 2011; 9:197-207.

184. Casado-Zapico S, Martin V, Garcia-Santos G, RodriguezBlanco J, Sanchez-Sanchez AM, Luno E, Suarez C, Garcia-Pedrero JM, Menendez ST, Antolin I, Rodriguez C. Regulation of the expression of death receptors and their ligands by melatonin in haematological cancer cell lines and in leukaemia cells from patients. J Pineal Res. 2011; 50:345-355.

185. Sanchez-Sanchez AM, Martin V, Garcia-Santos G, Rodriguez-Blanco J, Casado-Zapico S, Suarez-Garnacho $\mathrm{S}$, Antolin I, Rodriguez C. Intracellular redox state as determinant for melatonin antiproliferative vs cytotoxic effects in cancer cells. Free Radical Res. 2011; 45:13331341.

186. Martín V, Sanchez-Sanchez AM, Herrera F, GomezManzano C, Fueyo J, Alvarez-Vega MA, Antolín I, Rodriguez C. Melatonin-induced methylation of the ABCG2/BCRP promoter as a novel mechanism to overcome multidrug resistance in brain tumour stem cells. Br J Cancer. 2013; 108:2005-2012.

187. Casado-Zapico S, Rodriguez-Blanco J, Garcia-Santos G, Martin V, Sanchez-Sanchez AM, Antolin I, Rodriguez C. Synergistic antitumor effect of melatonin with several chemotherapeutic drugs on human Ewing sarcoma cancer cells: Potentiation of the extrinsic apoptotic pathway. J Pineal Res. 2010; 48:72-80. 
188. Barni S, Lissoni P, Cazzaniga M, Ardizzoia A, Meregalli S, Fossati V, Fumagalli L, Brivio F, Tancini G. A randomized study of low-dose subcutaneous interleukin-2 plus melatonin versus supportive care alone in metastatic colorectal cancer patients progressing under 5-fluorouracil and folates. Oncology. 1995; 52:243-245.

189. Lissoni P, Barni S, Meregalli S, Fossati V, Cazzaniga M, Esposti D, Tancini G. Modulation of cancer endocrine therapy by melatonin: A phase II study of tamoxifen plus melatonin in metastatic breast cancer patients progressing under tamoxifen alone. Br J Cancer. 1995; 71:854-6.

190. Lissoni P, Barni S, Mandala M, Ardizzoia A, Paolorossi F, Vaghi M, Longarini R, Malugani F, Tancini G. Decreased toxicity and increased efficacy of cancer chemotherapy using the pineal hormone melatonin in metastatic solid tumour patients with poor clinical status. Eur J Cancer. 1999; 35:1688-1692.

191. Lissoni P, Chilelli M, Villa S, Cerizza L, Tancini G. Five years survival in metastatic non-small cell lung cancer patients treated with chemotherapy alone or chemotherapy and melatonin: A randomized trial. J Pineal Res. 2003; 35:12-15.

192. Cerea G, Vaghi M, Ardizzoia A, Villa S, Bucovec R, Mengo S, Gardani G, Tancini G, Lissoni P. Biomodulation of cancer chemotherapy for metastatic colorectal cancer: A randomized study of weekly low-dose irinotecan alone versus irinotecan plus the oncostatic pineal hormone melatonin in metastatic colorectal cancer patients progressing on 5-fluorouracil-containing combinations. Anticancer Res. 2003; 23:1951-1954.

193. Innominato PF, Lim AS, Palesh O, Clemons M, Trudeau M, Eisen A, Wang C, Kiss A, Pritchard KI, Bjarnason GA. The effect of melatonin on sleep and quality of life in patients with advanced breast cancer. Support Care Cancer. 2016; 24:1097-1105.

194. Hansen MV, Andersen LT, Madsen MT, Hageman I,
Rasmussen LS, Bokmand S, Rosenberg J, Gogenur I. Effect of melatonin on depressive symptoms and anxiety in patients undergoing breast cancer surgery: A randomized, double-blind, placebo-controlled trial. Breast Cancer Res Treat. 2014; 145:683-695.

195. Madsen MT, Hansen MV, Andersen LT, Hageman I, Rasmussen LS, Bokmand S, Rosenberg J, Gogenur I. Effect of melatonin on sleep in the perioperative period after breast cancer surgery: A randomized, double-blind, placebocontrolled trial. J Clin Sleep Med. 2016; 12:225-233.

196. Chen WY, Giobbie-Hurder A, Gantman K, Savoie J, Scheib R, Parker LM, Schernhammer ES. A randomized, placebocontrolled trial of melatonin on breast cancer survivors: Impact on sleep, mood, and hot flashes. Breast Cancer Res Treat. 2014; 145:381-388.

197. Di Bella G, Mascia F, Ricchi A, Colori B. Evaluation of the safety and efficacy of the first-line treatment with somatostatin combined with melatonin, retinoids, vitamin D3, and low doses of cyclophosphamide in 20 cases of breast cancer: A preliminary report. Neuroendocrinol Lett. 2013; 34:660-668.

198. Schernhammer ES, Giobbie-Hurder A, Gantman K, Savoie J, Scheib R, Parker LM, Chen WY. A randomized controlled trial of oral melatonin supplementation and breast cancer biomarkers. Cancer Causes Control. 2012; 23:609-616.

199. Rasmussen CL, Olsen MK, Johnsen AT, Petersen MA, Lindholm H, Andersen L, Villadsen B, Groenvold M, Pedersen L. Effects of melatonin on physical fatigue and other symptoms in patients with advanced cancer receiving palliative care: A double-blind placebo-controlled crossover trial. Cancer. 2015; 121:3727-3736. 